TITLE:

Fluorinated microgel star polymers as fluorous nanocapsules for the encapsulation and release of perfluorinated compounds

$\operatorname{AUTHOR}(S)$ :

Koda, Yuta; Terashima, Takaya; Sawamoto, Mitsuo

CITATION:

Koda, Yuta ... [et al]. Fluorinated microgel star polymers as fluo rous nanocapsules for the encapsulation and release of perfluorinated compounds. Polymer chemistry 2015, 6(31): 5663-5674

ISSUE DATE:

2015-02-09

URL:

http://hdl.handle.net/2433/202832

RIGHT:

This journal is (c) The Royal Society of Chemistry 2015; This is an accepted manuscript of the article is available at http://dx.doi.org/10.1039/C5PY00113G.; The full-text file will be made open to the public on 05 Feb 2016 in accordance with publisher's 'Terms and Conditions for Self-Archiving'.; この論文は出版社版でありません。引用の際には出版社版 をご確認ご利用ください。; This is not the published version. Please cite only the published version. 


\section{Fluorinated Microgel Star Polymers as Fluorous Nanocapsules for Encapsulation and Release of Perfluorinated Compounds}

Yuta Koda, Takaya Terashima,* and Mitsuo Sawamoto*

*Corresponding Author

Department of Polymer Chemistry, Graduate School of Engineering, Kyoto University

Katsura, Nishikyo-ku, Kyoto 615-8510, JAPAN

Tel: +81-75-383-2600, Fax: +81-75-383-2601

E-mail: terashima@living.polym.kyoto-u.ac.jp,sawamoto@star.polym.kyoto-u.ac.jp

\section{Abstract}

Fluorinated microgel star polymers were designed and synthesized as fluorous nanocapsules for the encapsulation and release of perfluorinated compounds. Five types of these fluorous star polymers were obtained by ruthenium-catalyzed linking reaction of chlorine-capped poly(methyl methacrylate) arms (macroinitiators) with a perfluorinated dimethacrylate linker and a perfluorinated methacrylate $\left(\mathrm{R}_{\mathrm{F}} \mathrm{MA}\right)$, so as to tune the in-core fluorous properties depending on the latter structure and fluorine content. ${ }^{19} \mathrm{~F}$ nuclear magnetic resonance and ${ }^{19} \mathrm{~F}$ spin-spin relaxation time $\left(T_{2}\right)$ measurements revealed that the mobility of the in-core perfluorinated pendants derived from $\mathrm{R}_{\mathrm{F}} \mathrm{MA}$ decreased with increasing the number of fluorine and carbon atoms, or the pendant length. The cores effectively recognized and encapsulated perfluorinated guest compounds (e.g., perfluorooctane and perfluoromethylcyclohexane), and the encapsulation depended on the fluorous properties of the structures and fluorous nature of $\mathrm{R}_{\mathrm{F}} \mathrm{MA}$ and the guests. For example, encapsulation was promoted with increasing the number of in-core fluorine and $\mathrm{CF}_{3}$ groups, and typically the core with perfluorodecyl pendants successfully captured perfluorinated esters and ketones. In addition, fluorinated star polymers could reversibly capture and thermo-responsively release a perfluorinated guest, indicating the encapsulation is selective but dynamic and stimuli-responsive.

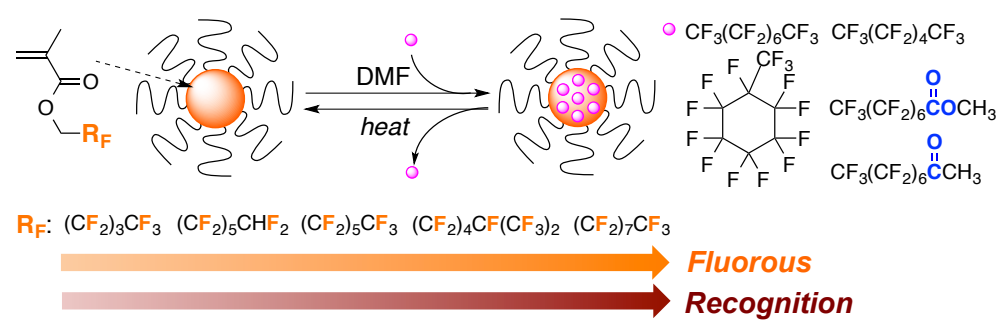




\section{Introduction}

"Fluorophilicity" is a key character of perfluorinated compounds and related materials, which are generally immiscible with hydrophobic (lipophilic) and hydrophilic solvents and compounds. $^{1-15}$ Because of this unique feature, perfluorinated materials are widely employed in industry and academic research; e.g., as water/oil repellents, surfactants, and surface coating agents, ${ }^{5,6}$ as well as key players in catalysis (for facile product separation, etc.), ${ }^{2-4,7}$ molecular recognition, ${ }^{8-10,12,13,14}$ and unique self-assembly. ${ }^{11-13}$ In particular, the functionalization of perfluorinated polymers with hydrophobic and/or hydrophilic segments is promising in creating globular macromolecules with fluorous inner compartments that are fully solubilized and/or dispersed in common organic solvents and water. ${ }^{8-13}$ Such fluorous compartments have been created within microgel-core star polymers, ${ }^{8,9}$ micelles, ${ }^{11-13}$ and the related self-assembly molecules, ${ }^{10,14}$ typically applicable to molecular encapsulation vessels.

Microgel-core star polymers possess covalently crosslinked microgels in the center that are solubilized and covered with plenty of linear arm polymers $(10-100),{ }^{16-22}$ in sharp contrast to micelles, vesicles, polymersomes, and nanogels that are based on the physical association of amphiphilic and/or functional polymers. ${ }^{23}$ The microgel cores of star polymers have large free spaces and lots of cavities ${ }^{22}$ to afford functional compartments that typically serve as nanocapsules for molecular capture and release and nanoreactors for catalysis. ${ }^{8,9,16,17,24-29}$ In general, microgel star polymers are obtained from the cross-linking reaction of living linear polymers or macroinitiators (arm) with divinyl monomers (core-forming agent) in living polymerization. ${ }^{30-34}$ Focusing on the high versatility and functionality tolerance, we have employed ruthenium-catalyzed living radical polymerization ${ }^{30}$ for the arm-linking reaction with functional linking agents and monomers, to directly produce various core-functionalized star polymers with amide, ${ }^{24}$ phosphine, ${ }^{25-27}$ amine ${ }^{27}$ hydroxyl, ${ }^{24,27}$ ionic, $^{28}$ and perfluorinated groups. ${ }^{8,9}$ Importantly, the arm-linking method not only gives functionalized microgels but also affords the efficient and local accumulation of functional groups into microgel cores.

In particular, fluorinated microgel star polymers have been recently developed as fluorous compartments soluble in organic solvents ${ }^{8}$ and aqueous media ${ }^{9}$ to encapsulate and separate perfluorinated guest compounds. The fluorous microgels were created by the accumulation of a perfluorinated alkane methacrylate (13FOMA) and the solubility was controlled by the surrounding arm polymers: i.e., hydrophobic poly(methyl methacrylate) arm star polymers were soluble in organic solvents, ${ }^{8}$ while amphiphilic and hydrophilic poly(ethylene glycol) arm counterparts were soluble in both organic solvents and aqueous media. ${ }^{9}$ As a result, fluorinated microgel star polymers (host) efficiently and selectively encapsulated perfluorinated guest compounds (e.g., perfluorooctane: PFO, perfluorooctanoic acid: PFOA) into the cores in DMF or water via fluorous 
host-guest interaction. Additionally, they released the guests from the core by reducing the fluorous interaction with $\mathrm{CHCl}_{3}$ addition. ${ }^{19} \mathrm{~F}$ nuclear magnetic resonance (NMR) measurements would allow us to evaluate a series of fluorous molecular recognition and the mobility of in-core perfluorinated alkyl pendants with ${ }^{19} \mathrm{~F}$ spin-latice and/or spin-spin relaxation time $\left(T_{1}, T_{2}\right)$. The dynamics characterization revealed that the accumulation of 13FOMA into microgel cores reduced the thermal mobility of the in-core perfluorinated pendants to result in stable fluorous compartments. $^{8} \quad$ The fluorous microgels can thus efficiently recognize and tightly enclose perfluorinated guest compounds.

Herein, we report the synthesis of various fluorinated microgel star polymers (S1 - S5) via living radical polymerization to create fluorous nanocapsules for the capture and stimuli-responsive release of perfluorinated compounds in organic media (Scheme 1). The in-core fluorous properties are effectively controlled with various perfluorinated alkyl methacrylates ( $\left.\mathrm{R}_{\mathrm{F}} \mathrm{MA}\right)$, affording the efficient recognition of various perfluorinated guest compounds.

$\mathbf{S 1}$ - S5 were directly prepared by ruthenium-catalyzed linking reaction of a chlorine-capped poly(methyl methacrylate) (PMMA-Cl) with a perfluorinated alkyl spacer dimethacrylate (12FODMA) in the presence of $\mathrm{R}_{\mathrm{F}} \mathrm{MA}$. The star polymers were characterized by size exclusion chromatography coupled with multi-angle laser light scattering (SEC-MALLS) and ${ }^{1} \mathrm{H}$ and ${ }^{19} \mathrm{~F}$ NMR spectroscopy. Confirmed by ${ }^{19} \mathrm{~F} T_{2}$ measurements, the mobility of in-core perfluorinated pendants decreased with increasing the number of fluorine atom and $\mathrm{CF}_{3}$ end-group in $\mathrm{R}_{\mathrm{F}} \mathrm{MA}$. Fluorinated star polymers efficiently encapsulated perfluorinated alkanes and the derivatives with functional groups such as ester and ketone, where the fluorous recognition is dependent on in-core $\mathrm{R}_{\mathrm{F}} \mathrm{MA}$ species. The key was to increase fluorous interaction between the perfluorinated pendants and guest molecules.

\section{Scheme 1}




\section{Experimental Section}

\section{Materials}

For Monomer Synthesis and Perfluorinated Guests. 1H,1H,2H,2H-nonafluoro-1-hexanol (TCI, purity > 97\%), 1H,1H,7H-dodecafluoro-1-heptanol (TCI, purity > 97\%), $1 H, 1 H, 2 H, 2 H$-perfluoro-7-methyloctan-1-ol (Wako), $1 H, 1 H, 2 H, 2 H$-heptadecafluoro-1-decanol (TCI, purity $>96 \%$ ), perfluoromethylcyclohexane (PFMCH: TCI, purity $>95 \%$ ), perfluorooctane (PFO: Aldrich, purity > 98\%), perfluorohexane (PFH: TCI, purity > 95\%), methyl perfluorooctanoate (PFO-ester: TCI, purity > 97\%), methyl perfluoroheptyl ketone (PFHp-ketone: TCI, purity $>95 \%$ ), and $1 H, 1 H$-perfluoro-1-octanol (PFO-OH: Aldrich, purity $>98 \%$ ) were used as received. Methacryloyl chloride (TCI, purity $>80.0 \%$ ) and triethylamine (TCI, purity $>99.0 \%$ ) were purified by distillation before use. Tetrahydrofuran (Wako, dyhydrated), dichloromethane (Wako, dehydrated), ethyl acetate (Wako, purity $>99.5 \%$ ), and hexane (Wako, purity $>96 \%$ ) were used as received.

For Star Polymer Synthesis. Methyl methacrylate (MMA: TCI, purity > 99\%) was dried overnight over calcium chloride and purified by distillation from calcium hydride before use. $1 H, 1 H, 2 H, 2 H$-Perfluorooctyl methacrylate (13FOMA: Wako, purity > 95\%) was purified by column chromatography charged with inhibitor remover (Aldrich) and purged by argon before use. 2,2,3,3,4,4,5,5,6,6,7,7-dodecafluoro-1,8,-octanediol dimethacrylate (12FODMA) was prepared according to the previous literature ${ }^{8}$ and degassed before use. $1 H, 1 H, 2 H, 2 H$-Perfluorohexcyl methacrylate (9FHxMA), 1H,1H,7H-perfluoro-1-heptyl methacrylate (12FHpMA), $1 H, 1 H, 2 H, 2 H$-perfluoro-7-methyloctyl methacrylate (15FMOMA), and $1 H, 1 H, 2 H, 2 H$-perfluorodecyl methacrylate (17FDeMA) were prepared as shown below and degassed before use. Ethyl-2-chloro-2-phenylacetate (ECPA: Aldrich, purity > 97\%) was purified by distillation under reduced pressure before use. $\mathrm{Ru}(\mathrm{Ind}) \mathrm{Cl}\left(\mathrm{PPh}_{3}\right)_{2}$ (Ind: indenyl, Aldrich) was handled in a grove box under a moisture- and oxygen-free argon atmosphere $\left(\mathrm{H}_{2} \mathrm{O}<1 \mathrm{ppm}, \mathrm{O}_{2}<1\right.$ ppm). $\quad n-\mathrm{Bu}_{3} \mathrm{~N}$ (TCI, purity $>98 \%$ ) was purged by argon before use. Tetralin (1,2,3,4-tetrahydronaphthalene: TCI, purity $>98 \%)$, as an internal standard for the conversion of 12FODMA and perfluorinated monomers determined by ${ }^{1} \mathrm{H}$ NMR, was dried over calcium chloride overnight and distilled from calcium hydride. Toluene (Kishida Chemical, purity $>99 \%$ ) was purified by passing it through a purification column (Solvent Dispensing System, glass contour, HANSEN\&CO., LTD) before use. 


\section{Characterization}

Molecular weight distribution curves, number-average molecular weight $\left(M_{\mathrm{n}}\right)$, and dispersity $\left(M_{\mathrm{w}} / M_{\mathrm{n}}\right)$ of the polymers were measured by SEC (shodex GPC-104) in THF at $40{ }^{\circ} \mathrm{C}$ (flow rate: 0.3 $\mathrm{mL} / \mathrm{min}$ ) on three polystyrene gel columns (shodex LF-404: exclusion limit $=2 \times 10^{6} \mathrm{~g} / \mathrm{mol}$; particle size $=6 \mu \mathrm{m}$; pore size $=3000 \AA$; $0.46 \mathrm{~cm}$ i.d. $\times 25 \mathrm{~cm}$ ) that were connected to a shodex DU-H2000 pump, a shodex RI-74 refractive index detector, and a shodex UV-41 UV detector set at $250 \mathrm{~nm}$. The columns were calibrated against 13 standard poly(MMA) samples (Polymer Laboratories; $\left.M_{\mathrm{n}}=620-1200000 ; M_{\mathrm{w}} / M_{\mathrm{n}}=1.02-1.30\right)$. ${ }^{1} \mathrm{H}$ and ${ }^{19} \mathrm{~F}$ NMR spectra were recorded in $\mathrm{CDCl}_{3}, \mathrm{CD}_{2} \mathrm{Cl}_{2}$, and DMF- $d_{7}$ at room temperature or $30{ }^{\circ} \mathrm{C}$ on a JEOL JNM-ECA500 spectrometer, operating at $500.16\left({ }^{1} \mathrm{H}\right)$ or $470.62\left({ }^{19} \mathrm{~F}\right) \mathrm{MHz}$. For characterization and molecular encapsulation experiments, polymers were purified by preparative SEC in $\mathrm{CHCl}_{3}$ at room temperature (flow rate: $10 \mathrm{~mL} / \mathrm{min}$ ) on a polystyrene gel column $\left(\mathrm{K}-5003\right.$ : exclusion limit $=7 \times 10^{4}$ $\mathrm{g} / \mathrm{mol}$; particle size $=15 \mu \mathrm{m} ; 5.0 \mathrm{~cm}$ i.d. $\times 30 \mathrm{~cm}$ ) that was connected to a Jasco PU-2086 precision pump, a Jasco RI-2031 refractive index detector, and a Jasco UV-2075 UV/vis detector set at 250 nm. Absolute weight-average molecular weight $\left(M_{\mathrm{w}}\right)$ and radius of gyration $\left(R_{\mathrm{g}}\right)$ of star polymers were determined by multi-angle laser light scattering (MALLS) equipped with SEC on a Dawn E instrument (Wyatt Technology, Ga-As laser, $\lambda=690 \mathrm{~nm}$ ). The SEC was performed in DMF containing $10 \mathrm{mM} \mathrm{LiBr}$ at $40{ }^{\circ} \mathrm{C}$ (flow rate: $1 \mathrm{~mL} / \mathrm{min}$ ) on three linear-type polystyrene gel columns (shodex KF-805L: exclusion limit $=4 \times 10^{6} \mathrm{~g} / \mathrm{mol}$; particle size $=10 \mu \mathrm{m}$; pore size $=5000 \AA$; 0.8 $\mathrm{cm}$ i.d. $\times 30 \mathrm{~cm})$ that were connected to a Jasco PU-2080 precision pump, a Jasco RI-1530 refractive index detector, and a Jasco UV-1570 UV/vis detector set at $270 \mathrm{~nm}$. The refractive index increment $(d n / d c)$ was measured in DMF at $40{ }^{\circ} \mathrm{C}$ on an Optilab DSP refractometer (Wyatt Technology, $\lambda=690 \mathrm{~nm}, c<3.3 \mathrm{mg} / \mathrm{mL})$.

\section{Synthesis of Perfluorinated Monomers}

9FHxMA. In $200 \mathrm{~mL}$ round-bottomed flask filled with argon, methacryloyl chloride (143.3 mmol, $13.9 \mathrm{~mL}$ ) was added to a solution of $1 H, 1 H, 2 H, 2 H$-nonafluoro-1-hexanol (95.5 mmol, 25.2 g) and trientylamine $(143.3 \mathrm{mmol}, 19.9 \mathrm{~mL})$ in dry THF $(50 \mathrm{~mL})$ at $0{ }^{\circ} \mathrm{C}$. The reaction mixture was stirred at $25^{\circ} \mathrm{C}$ for $24 \mathrm{~h}$. After the evaporation of the reaction solution, diethyl ether $(150 \mathrm{~mL})$ and distilled water $(150 \mathrm{~mL})$ were poured into the flask. The aqueous phase was separated and extracted by diethyl ether $(150 \mathrm{~mL})$, and the ether extracts were combined with the organic layer. The combined organic phase was washed with water three times. After the ether was removed by evaporation, the crude product was purified by silica gel column chromatography (the bottom and top layers were covered with sodium sulfate) with hexane/ethyl acetate $(10 / 1, \mathrm{v} / \mathrm{v})$ as an eluent. The solution was evaporated in vacuo to dryness to give colorless liquid of 9FHxMA. Yield: $21.9 \mathrm{~g}$ 
(69\%). $\delta_{\mathrm{H}}\left(500 \mathrm{MHz} ; \mathrm{CDCl}_{3}\right.$; chloroform) $6.13(1 \mathrm{H}, \mathrm{m}), 5.60(1 \mathrm{H}, \mathrm{m}), 4.45(2 \mathrm{H}, \mathrm{t}, J=6.6 \mathrm{~Hz})$, $2.51\left(2 \mathrm{H}, \mathrm{tt},{ }^{3} J_{\mathrm{FH}}=18.3,{ }^{3} J_{\mathrm{HH}}=6.6 \mathrm{~Hz}\right) 1.94(3 \mathrm{H}, \mathrm{t}, J=1.4 \mathrm{~Hz}) . \quad \delta_{\mathrm{C}}\left(125 \mathrm{MHz} ; \mathrm{CDCl}_{3}\right.$; chloroform) $166.9(\mathrm{C}), 136.0(\mathrm{C}), 126.0\left(\mathrm{CH}_{2}\right), 117.6\left(\mathrm{CH}_{2} \mathrm{CF}_{2}, \mathrm{tt},{ }^{1} J_{\mathrm{FC}}=255.5,{ }^{2} J_{\mathrm{FC}}=32.4 \mathrm{~Hz}\right)$, $117.1\left(\mathrm{CF}_{3}, \mathrm{qt},{ }^{1} J_{\mathrm{FC}}=287.9,{ }^{2} J_{\mathrm{FC}}=33.6 \mathrm{~Hz}\right), 112.9-106.7\left(\mathrm{CF}_{2} \mathrm{CF}_{2}, \mathrm{~m}\right), 56.5\left(\mathrm{CH}_{2}\right), 30.5\left(\mathrm{CH}_{2}, \mathrm{t}\right.$, $\left.{ }^{2} J_{\mathrm{FC}}=22.8 \mathrm{~Hz}\right), 17.9\left(\mathrm{CH}_{3}\right) . \quad \delta_{\mathrm{F}}\left(470 \mathrm{MHz} ; \mathrm{CDCl}_{3} ; \mathrm{CF}_{3} \mathrm{COOH}\right)-82.2\left(3 \mathrm{~F}, \mathrm{tt},{ }^{3} J_{\mathrm{FF}}=9.9,{ }^{4} J_{\mathrm{FF}}=3.6\right.$ $\mathrm{Hz}),-114.8$ (2F, m), -125.6 (2F, m), -127.0 (2F, m).

12FHрMA. In $300 \mathrm{~mL}$ round-bottomed flask filled with argon, methacryloyl chloride (222.7 mmol, $21.5 \mathrm{~mL}$ ) was added to a solution of $1 H, 1 H, 7 H$-dodecafluoro-1-heptanol (148.4 mmol, $49.3 \mathrm{~g})$ and trientylamine $(222.7 \mathrm{mmol}, 31.0 \mathrm{~mL})$ in dry THF $(75 \mathrm{~mL})$ at $0{ }^{\circ} \mathrm{C}$. The reaction mixture was stirred at $25{ }^{\circ} \mathrm{C}$ for $24 \mathrm{~h}$. After the evaporation of the reaction solution, diethyl ether $(150 \mathrm{~mL})$ and distilled water $(150 \mathrm{~mL})$ were poured into the flask. The aqueous phase was separated and extracted by diethyl ether $(150 \mathrm{~mL})$, and the ether extracts were combined with the organic layer. The combined organic phase was washed with water three times. After the ether was removed by evaporation, the crude product was purified by silica gel column chromatography (the bottom and top layers were covered with sodium sulfate) with hexane/ethyl acetate $(10 / 1, \mathrm{v} / \mathrm{v})$ as an eluent. The solution was evaporated in vacuo to dryness to give colorless liquid of 12FHpMA. Yield: $20.1 \mathrm{~g} \mathrm{(34 \% ).} \quad \delta_{\mathrm{H}}\left(500 \mathrm{MHz} ; \mathrm{CDCl}_{3}\right.$; chloroform) $6.21(1 \mathrm{H}, \mathrm{m}), 6.04(1 \mathrm{H}$, tt, $\left.{ }^{2} J_{\mathrm{FH}}=51.8,{ }^{3} J_{\mathrm{FH}}=5.2 \mathrm{~Hz}\right), 5.70(1 \mathrm{H}, \mathrm{m}), 4.65\left(2 \mathrm{H}, \mathrm{t},{ }^{3} J_{\mathrm{FH}}=13.5 \mathrm{~Hz}\right), 1.97(3 \mathrm{H}, \mathrm{t}, J=1.2 \mathrm{~Hz}) . \quad \delta_{\mathrm{C}}$ (125 MHz; $\mathrm{CDCl}_{3}$; chloroform) $166.8(\mathrm{C}), 135.0(\mathrm{C}), 127.7\left(\mathrm{CH}_{2}\right), 111.2\left(\mathrm{CH}_{2} \mathrm{CF}_{2}, \mathrm{tt},{ }^{1} J_{\mathrm{FC}}=270.5\right.$, $\left.{ }^{2} J_{\mathrm{FC}}=32.4 \mathrm{~Hz}\right), 107.8\left(\mathrm{CHF}_{2}, \mathrm{tt},{ }^{1} J_{\mathrm{FC}}=254.9,{ }^{2} J_{\mathrm{FC}}=31.2 \mathrm{~Hz}\right), 60.1\left(\mathrm{CH}_{2}, \mathrm{t},{ }^{2} J_{\mathrm{FC}}=27.6 \mathrm{~Hz}\right), 18.0$ $\left(\mathrm{CH}_{3}\right) . \quad \delta_{\mathrm{F}}\left(470 \mathrm{MHz} ; \mathrm{CDCl}_{3} ; \mathrm{CF}_{3} \mathrm{COOH}\right)-120.5(2 \mathrm{~F}, \mathrm{~m}),-123.2(2 \mathrm{~F}, \mathrm{~m}),-124.5(4 \mathrm{~F}$, br s $),-130.6$ $(2 \mathrm{~F}, \mathrm{~m}),-138.2\left(2 \mathrm{~F}, \mathrm{dm},{ }^{2} J_{\mathrm{HF}}=51.7 \mathrm{~Hz}\right)$.

15FMOMA. In $300 \mathrm{~mL}$ round-bottomed flask filled with argon, methacryloyl chloride (71.0 mmol, $6.9 \mathrm{~mL}$ ) was added to a solution of $1 H, 1 H, 2 H, 2 H$-perfluoro-7-methyloctan-1-ol (47.3 mmol, $19.6 \mathrm{~g})$ and trientylamine $(71.0 \mathrm{mmol}, 9.9 \mathrm{~mL})$ in dry dichloromethane $(50 \mathrm{~mL})$ at $0{ }^{\circ} \mathrm{C}$. The reaction mixture was stirred at $25{ }^{\circ} \mathrm{C}$ for $24 \mathrm{~h}$. After the evaporation of the reaction solution, diethyl ether $(150 \mathrm{~mL})$ and distilled water $(150 \mathrm{~mL})$ were poured into the flask. The aqueous phase was separated and extracted by diethyl ether $(150 \mathrm{~mL})$, and the ether extracts were combined with the organic layer. The combined organic phase was washed with water three times. After the ether was removed by evaporation, the crude product was purified by silica gel column chromatography (the bottom and top layers were covered with sodium sulfate) with hexane/ethyl acetate $(10 / 1, \mathrm{v} / \mathrm{v})$ as an eluent. The solution was evaporated in vacuo to dryness to give colorless liquid of 15FMOMA. Yield: $20.8 \mathrm{~g}(91 \%) . \quad \delta_{\mathrm{H}}\left(500 \mathrm{MHz}: \mathrm{CDCl}_{3}\right.$; chloroform) $6.13(1 \mathrm{H}, \mathrm{m})$, $5.61(1 \mathrm{H}, \mathrm{m}), 4.45(2 \mathrm{H}, \mathrm{t}, J=6.3 \mathrm{~Hz}), 2.51\left(2 \mathrm{H}, \mathrm{tt},{ }^{3} J_{\mathrm{FH}}=18.3,{ }^{3} J_{\mathrm{HH}}=6.3 \mathrm{~Hz}\right) 1.95(3 \mathrm{H}, \mathrm{t}, J=1.2$ $\mathrm{Hz}) . \quad \delta_{\mathrm{C}}\left(125 \mathrm{MHz} ; \mathrm{CDCl}_{3}\right.$; chloroform $) 167.0(\mathrm{C}), 136.0(\mathrm{C}), 126.3\left(\mathrm{CH}_{2}\right), 118.9\left(\mathrm{CF}_{3}, \mathrm{qd},{ }^{1} J_{\mathrm{FC}}=\right.$ 
$\left.290,{ }^{2} J_{\mathrm{FC}}=26.4 \mathrm{~Hz}\right), 117.8\left(\mathrm{CH}_{2} \mathrm{CF}_{2}, \mathrm{tt}^{1} J_{\mathrm{FC}}=256.7,{ }^{2} J_{\mathrm{FC}}=32.4 \mathrm{~Hz}\right), 115-108\left(\mathrm{CF}_{2}, \mathrm{~m}\right), 90.6(\mathrm{CF}$, dsep, $\left.{ }^{1} J_{\mathrm{FC}}=226.7,{ }^{2} J_{\mathrm{FC}}=32.4 \mathrm{~Hz}\right), 56.7\left(\mathrm{CH}_{2}\right), 30.7\left(\mathrm{CH}_{2}, \mathrm{t},{ }^{2} J_{\mathrm{FC}}=21.6 \mathrm{~Hz}\right), 18.1\left(\mathrm{CH}_{3}\right) . \quad \delta_{\mathrm{F}}(470$ $\left.\mathrm{MHz} ; \mathrm{CDCl}_{3} ; \mathrm{CF}_{3} \mathrm{COOH}\right)-72.9$ (6F, m), -114.6 (2F, m), -116.1 (2F, br s), -121.7 (2F, br s), -124.2 (2F, br s), $-187.1(2 \mathrm{~F}$, br s).

17FDeMA. In $300 \mathrm{~mL}$ round-bottomed flask filled with argon, methacryloyl chloride (80.9 mmol, $7.8 \mathrm{~mL}$ ) was added to a solution of $1 H, 1 H, 2 H, 2 H$-heptadecafluoro-1-decanol (53.9 mmol, 25 g) and trientylamine $(80.9 \mathrm{mmol}, 11.2 \mathrm{~mL})$ in dry THF $(75 \mathrm{~mL})$ at $0{ }^{\circ} \mathrm{C}$. The reaction mixture was stirred at $25{ }^{\circ} \mathrm{C}$ for $24 \mathrm{~h}$. After the evaporation of the reaction solution, diethyl ether $(150 \mathrm{~mL})$ and distilled water $(150 \mathrm{~mL})$ were poured into the flask. The aqueous phase was separated and extracted by diethyl ether $(150 \mathrm{~mL})$, and the ether extracts were combined with the organic layer. The combined organic phase was washed with water three times. After the ether was removed by evaporation, the crude product was purified by silica gel column chromatography (the bottom and top layers were covered with sodium sulfate) with hexane/ethyl acetate (10/1, v/v) as an eluent. The solution was evaporated in vacuo to dryness to give colorless liquid of 17FDeMA. Yield: $22.8 \mathrm{~g}(80 \%) . \quad \delta_{\mathrm{H}}\left(500 \mathrm{MHz} ; \mathrm{CDCl}_{3}\right.$; chloroform) $6.14(1 \mathrm{H}, \mathrm{br} \mathrm{s}), 5.61(1 \mathrm{H}, \mathrm{m}), 4.46(2 \mathrm{H}, \mathrm{t}, J=$ $6.2 \mathrm{~Hz}), 2.51\left(2 \mathrm{H}, \mathrm{tt},{ }^{3} J_{\mathrm{FH}}=18.1,{ }^{3} J_{\mathrm{HH}}=6.7 \mathrm{~Hz}\right) 1.95\left({ }^{3} \mathrm{H}, \mathrm{t}, J=1.4\right) . \quad \delta_{\mathrm{C}}\left(125 \mathrm{MHz} ; \mathrm{CDCl}_{3}\right.$; chloroform) $167.0(\mathrm{C}), 136.0(\mathrm{C}), 126.3\left(\mathrm{CH}_{2}\right), 117.8\left(\mathrm{CH}_{2} \mathrm{CF}_{2}, \mathrm{tt},{ }^{1} J_{\mathrm{FC}}=256.7,{ }^{2} J_{\mathrm{FC}}=32.4 \mathrm{~Hz}\right)$, $117.4\left(\mathrm{CF}_{3}, \mathrm{qt},{ }^{1} J_{\mathrm{FC}}=297.9,{ }^{2} J_{\mathrm{FC}}=32.4 \mathrm{~Hz}\right), 114.2-106.1\left(\mathrm{CF}_{2}, \mathrm{~m}\right), 56.7\left(\mathrm{CH}_{2}\right), 30.7\left(\mathrm{CH}_{2}, \mathrm{t},{ }^{2} J_{\mathrm{FC}}\right.$ $=21.6 \mathrm{~Hz}), 18.1\left(\mathrm{CH}_{3}\right) . \quad \delta_{\mathrm{F}}\left(470 \mathrm{MHz} ; \mathrm{CDCl}_{3} ; \mathrm{CF}_{3} \mathrm{COOH}\right)-81.9(3 \mathrm{~F}$, br s), -114.6 (2F, br s), -122.7 (2F, br s), -123.0 (4F, br s), -123.8 (2F, br s), -124.6 (2F, br s), -127.2 (2F, br s).

\section{Synthesis of Fluorinated Microgel Star Polymers}

The synthesis of star polymers (S1-S5) were carried out by syringe technique under argon in baked round-bottomed flasks equipped with a three-way stopcock.

S1: In a $200 \mathrm{~mL}$ round-bottomed flask, $\mathrm{Ru}(\mathrm{Ind}) \mathrm{Cl}\left(\mathrm{PPh}_{3}\right)_{2}(0.220 \mathrm{mmol}, 171 \mathrm{mg})$ was placed. Into this flask, toluene $(58.1 \mathrm{~mL})$, tetralin $(4.7 \mathrm{~mL})$, a $400 \mathrm{mM}$ toluene solution of $n-\mathrm{Bu}_{3} \mathrm{~N}(2.2$ mmol, $5.5 \mathrm{~mL})$, MMA (441 mmol, $47.2 \mathrm{~mL})$, and ECPA (2.2 mmol, $0.38 \mathrm{~mL})$ were added sequentially in this order at $25^{\circ} \mathrm{C}$ under argon (total volume: $\left.116 \mathrm{~mL}\right)$. The solution $(25 \mathrm{~mL})$ was distributed into four $100 \mathrm{~mL}$ round-bottomed flasks to prepare PMMA arms for star polymers (S1, S2, S4, S5). The flask with $25 \mathrm{~mL}$ polymerization solution was placed in an oil bath at $80{ }^{\circ} \mathrm{C}$. After $14 \mathrm{~h}$ (48\% conversion: by ${ }^{1} \mathrm{H}$ NMR), the solution was evaporated in vacuo at $25{ }^{\circ} \mathrm{C}$ to give PMMA-Cl $\left(M_{\mathrm{n}}=12000, M_{\mathrm{w}} / M_{\mathrm{n}}=1.13,0.47 \mathrm{mmol}\right)$ with non-volatile agents (tetralin, $n-\mathrm{Bu}_{3} \mathrm{~N}$, and $\mathrm{Ru}$ catalyst). Into this flask, toluene $(18.7 \mathrm{~mL})$, a $1110 \mathrm{mM}$ toluene solution of 12FODMA (2.5 mmol, $2.25 \mathrm{~mL})$, and a $3290 \mathrm{mM}$ toluene solution of 9FHxMA (5.0 mmol, $1.5 \mathrm{~mL})$ were added at $25{ }^{\circ} \mathrm{C}$, and the flask was placed in an oil bath at $80{ }^{\circ} \mathrm{C}$. After $18 \mathrm{~h}$, the reaction was terminated by 
cooling the mixture to $-78{ }^{\circ} \mathrm{C}$ (conversion of 12FODMA/9FHxMA: $90 \% / 79 \%$ by ${ }^{1} \mathrm{H}$ NMR). The quenched reaction mixture was evaporated to dryness. The resulting crude was purified by preparative SEC in $\mathrm{CHCl}_{3}$ (to remove catalysts and unreacted arm residue and monomers) and dried under vacuum to give S1. Star yield (SEC): 78\%. $\quad d n / d c(\mathrm{DMF})=0.029 . \quad$ SEC-MALLS (DMF, $0.01 \mathrm{M} \mathrm{LiBr}): M_{\mathrm{w}}=461000 \mathrm{~g} / \mathrm{mol} ;$ arm numbers $=23 ; R_{\mathrm{g}}=13 \mathrm{~nm} . \delta_{\mathrm{H}}\left(500 \mathrm{MHz} ; \mathrm{CD}_{2} \mathrm{Cl}_{2}\right.$; dichloromethane) $7.3-7.1$ (aromatic), 6.2, 5.7 (olefin), $4.8-3.9$ (- $\left.\mathrm{COCH}_{2} \mathrm{CH}_{2} \mathrm{CF}_{2}-\right), 4.7-4.6$ $\left(-\mathrm{COCH}_{2} \mathrm{CF}_{2-}\right), 4.1-3.9\left(-\mathrm{COCH}_{2} \mathrm{CH}_{3}\right), 3.8-3.4\left(-\mathrm{OCH}_{3}\right), 3.4\left(-\mathrm{COCHPhCH}_{2}-\right), 2.7-2.3$ $\left(-\mathrm{COCH}_{2} \mathrm{CH}_{2} \mathrm{CF}_{2}\right), 2.1-1.4\left(-\mathrm{CH}_{2}-\right), 1.2-0.6\left(-\mathrm{CCH}_{3}\right) . \quad \delta_{\mathrm{F}}\left(470 \mathrm{MHz} ; \mathrm{CDCl}_{3} ; \mathrm{CF}_{3} \mathrm{COOH}\right)-81.9$ - -83.2 (- $\left.-\mathrm{CF}_{3}\right),-113.9--116.2\left(-\mathrm{CH}_{2} \mathrm{CH}_{2} \mathrm{CF}_{2}-\right),-119.9--121.2\left(-\mathrm{COCH}_{2} \mathrm{CF}_{2}-\right),-121.4--125.1$ $\left(-\mathrm{COCH}_{2} \mathrm{CF}_{2} \mathrm{CF}_{2} \mathrm{CF}_{2}-\right),-125.1--126.6\left(-\mathrm{CF}_{2} \mathrm{CF}_{2} \mathrm{CF}_{3}\right),-126.6--128.1\left(-\mathrm{CF}_{2} \mathrm{CF}_{3}\right)$.

S2: PMMA-Cl was prepared as shown in S1. Into the $100 \mathrm{~mL}$ round-bottomed flask containing PMMA-Cl $\left(M_{\mathrm{n}}=12000, M_{\mathrm{w}} / M_{\mathrm{n}}=1.13,0.47 \mathrm{mmol}\right)$ and non-volatile agents (tetralin, $n-\mathrm{Bu}_{3} \mathrm{~N}$, and $\mathrm{Ru}$ catalyst), toluene $(18.7 \mathrm{~mL})$, a $1110 \mathrm{mM}$ toluene solution of 12FODMA (2.5 mmol, $2.25 \mathrm{~mL})$, and a $2690 \mathrm{mM}$ toluene solution of 12FHpMA $(5.0 \mathrm{mmol}, 1.86 \mathrm{~mL})$ were added at $25^{\circ} \mathrm{C}$, and the flask was placed in an oil bath at $80{ }^{\circ} \mathrm{C}$. After $18 \mathrm{~h}$, the reaction was terminated by cooling the mixture to $-78{ }^{\circ} \mathrm{C}$ (total conversion: $85 \%$ by ${ }^{1} \mathrm{H}$ NMR). The quenched reaction mixture was evaporated to dryness. The resulting crude was purified by preparative $\mathrm{SEC}$ in $\mathrm{CHCl}_{3}$ (to remove catalysts and unreacted arm residue and monomers) and dried under vacuum to give S2. Star yield (SEC): 77\%. $\quad d n / d c(\mathrm{DMF})=0.032 . \quad$ SEC-MALLS $(\mathrm{DMF}, 0.01 \mathrm{M} \mathrm{LiBr}): M_{\mathrm{w}}=399000 \mathrm{~g} / \mathrm{mol}$; arm numbers $=19 ; R_{\mathrm{g}}=23 \mathrm{~nm} . \quad \delta_{\mathrm{H}}\left(500 \mathrm{MHz} ; \mathrm{CD}_{2} \mathrm{Cl}_{2}\right.$, dichloromethane) $7.3-7.1$ (aromatic), 6.3 - $5.8\left(-\mathrm{CHF}_{2}\right), 6.2,5.7$ (olefin), 4.8 - $3.9\left(-\mathrm{COCH}_{2} \mathrm{CF}_{2}-\right), 4.1-3.9\left(-\mathrm{COCH}_{2} \mathrm{CH}_{3}\right), 3.8-3.4$ $\left(-\mathrm{OCH}_{3}\right), 3.4\left(-\mathrm{COCHPhCH}_{2}-\right), 2.2-1.4\left(-\mathrm{CH}_{2}-\right), 1.2-0.4\left(-\mathrm{CCH}_{3}\right) . \quad \delta_{\mathrm{F}}\left(470 \mathrm{MHz} ; \mathrm{CDCl}_{3}\right.$; $\left.\mathrm{CF}_{3} \mathrm{COOH}\right)-116.0--121.5\left(-\mathrm{CH}_{2} \mathrm{CF}_{2}-\right),-122.0--127.2\left(-\mathrm{CF}_{2}-\right),-129.8--132.0\left(-\mathrm{CF}_{2} \mathrm{CHF}_{2}\right)$, $-137.4--139.6\left(-\mathrm{CHF}_{2}\right)$.

S4: PMMA-Cl was prepared as shown in S1. Into the $100 \mathrm{~mL}$ round-bottomed flask containing PMMA-Cl $\left(M_{\mathrm{n}}=12000, M_{\mathrm{w}} / M_{\mathrm{n}}=1.13,0.47 \mathrm{mmol}\right)$ and non-volatile agents (tetralin, $n-\mathrm{Bu}_{3} \mathrm{~N}$, and $\mathrm{Ru}$ catalyst), toluene $(18.7 \mathrm{~mL})$, a $1111 \mathrm{mM}$ toluene solution of 12FODMA (2.5 mmol, $2.25 \mathrm{~mL}$ ), and a $1670 \mathrm{mM}$ toluene solution of 15FMOMA (5.0 mmol, $3.0 \mathrm{~mL})$ were added at $25{ }^{\circ} \mathrm{C}$, and the flask was placed in an oil bath at $80{ }^{\circ} \mathrm{C}$. After $19 \mathrm{~h}$, the reaction was terminated by cooling the mixture to $-78{ }^{\circ} \mathrm{C}$ (conversion of 12FODMA/15FMOMA: 89\%/79\% by ${ }^{1} \mathrm{H}$ NMR). The quenched reaction mixture was evaporated to dryness. The resulting crude was purified by preparative SEC in $\mathrm{CHCl}_{3}$ (to remove catalysts and unreacted arm residue and monomers) and dried under vacuum to give S4. Star yield (SEC): 76\%. $\quad d n / d c(\mathrm{DMF})=0.026 . \quad$ SEC-MALLS (DMF, $0.01 \mathrm{M} \mathrm{LiBr}): M_{\mathrm{w}}=509000 \mathrm{~g} / \mathrm{mol} ;$ arm numbers $=25 ; R_{\mathrm{g}}=18 \mathrm{~nm} . \delta_{\mathrm{H}}\left(500 \mathrm{MHz} ; \mathrm{CD}_{2} \mathrm{Cl}_{2}\right.$; dichloromethane) $7.3-7.1$ (aromatic), 6.2, 5.7 (olefin), $4.8-3.9$ (- $\left.\mathrm{COCH}_{2} \mathrm{CH}_{2} \mathrm{CF}_{2}-\right)$, $4.7-4.6$ 
$\left(-\mathrm{COCH}_{2} \mathrm{CF}_{2}-\right), 4.1-3.9\left(-\mathrm{COCH}_{2} \mathrm{CH}_{3}\right), 3.8-3.4\left(-\mathrm{OCH}_{3}\right), 3.4\left(-\mathrm{COCHPhCH}_{2}-\right), 2.7-2.3$ $\left(-\mathrm{COCH}_{2} \mathrm{CH}_{2} \mathrm{CF}_{2}\right), 2.1-1.4\left(-\mathrm{CH}_{2}-\right), 1.2-0.4\left(-\mathrm{CCH}_{3}\right) . \quad \delta_{\mathrm{F}}\left(470 \mathrm{MHz} ; \mathrm{CDCl}_{3} ; \mathrm{CF}_{3} \mathrm{COOH}\right)-72.7$ - -74.4 (- $\left.-\mathrm{CF}_{3}\right),-113.7--115.7\left(-\mathrm{CH}_{2} \mathrm{CH}_{2} \mathrm{CF}_{2^{-}}\right),-115.7--126.8\left(-\mathrm{CF}_{2}-\right),-186.8--188.1$ $\left[-\mathrm{C} F\left(\mathrm{CF}_{3}\right)_{2}\right]$.

S5: PMMA-Cl was prepared as shown in S1. Into the $100 \mathrm{~mL}$ round-bottomed flask containing PMMA-Cl $\left(M_{\mathrm{n}}=12000, M_{\mathrm{w}} / M_{\mathrm{n}}=1.13,0.47 \mathrm{mmol}\right)$ and non-volatile agents (tetralin, $n-\mathrm{Bu}_{3} \mathrm{~N}$, and $\mathrm{Ru}$ catalyst), toluene $(18.7 \mathrm{~mL})$, a $1110 \mathrm{mM}$ toluene solution of 12FODMA (2.5 mmol, $2.25 \mathrm{~mL})$, and a $1490 \mathrm{mM}$ toluene solution of 17FDeMA $(5.0 \mathrm{mmol}, 3.35 \mathrm{~mL})$ were added at $25{ }^{\circ} \mathrm{C}$, and the flask was placed in an oil bath at $80{ }^{\circ} \mathrm{C}$. After $18 \mathrm{~h}$, the reaction was terminated by cooling the mixture to $-78{ }^{\circ} \mathrm{C}$ (conversion of 12 FODMA/17FDeMA: $90 \% / 82 \%$ by ${ }^{1} \mathrm{H}$ NMR). The quenched reaction mixture was evaporated to dryness. The resulting crude was purified by preparative $\mathrm{SEC}$ in $\mathrm{CHCl}_{3}$ (to remove catalysts and unreacted arm residue and monomers) and dried under vacuum to give S5. Star yield (SEC): 73\%. $\quad d n / d c(\mathrm{DMF})=0.026 . \quad$ SEC-MALLS (DMF, $0.01 \mathrm{M} \mathrm{LiBr}): M_{\mathrm{w}}=954000 \mathrm{~g} / \mathrm{mol} ;$ arm numbers $=42 ; R_{\mathrm{g}}=21 \mathrm{~nm} . \delta_{\mathrm{H}}\left(500 \mathrm{MHz} ; \mathrm{CD}_{2} \mathrm{Cl}_{2}\right.$; dichloromethane) $7.3-7.1$ (aromatic), 6.2, 5.7 (olefin), $4.8-3.9$ (- $\left.\mathrm{COCH}_{2} \mathrm{CH}_{2} \mathrm{CF}_{2}-\right), 4.7-4.6$ $\left(-\mathrm{COCH}_{2} \mathrm{CF}_{2-}\right), 4.1-3.9\left(-\mathrm{COCH}_{2} \mathrm{CH}_{3}\right), 3.8-3.4\left(-\mathrm{OCH}_{3}\right), 3.4\left(-\mathrm{COCHPhCH}_{2}-\right), 2.7-2.3$ $\left(-\mathrm{COCH}_{2} \mathrm{CH}_{2} \mathrm{CF}_{2}\right), 2.1-1.4\left(-\mathrm{CH}_{2}-\right), 1.2-0.4\left(-\mathrm{CCH}_{3}\right) . \quad \delta_{\mathrm{F}}\left(470 \mathrm{MHz}, \mathrm{CDCl}_{3} ; \mathrm{CF}_{3} \mathrm{COOH}\right)-81.7$ $--83.7\left(-\mathrm{CF}_{3}\right),-113.6--116.4\left(-\mathrm{CH}_{2} \mathrm{CF}_{2}-\right),-119.7--126.5\left(-\mathrm{CF}_{2}-\right),-126.7--129.0\left(-\mathrm{C}_{2} \mathrm{CF}_{3}\right)$.

\section{${ }^{19}$ F $T_{2}$ Measurements}

Degassed solutions of star polymers (S1-S5: $50 \mathrm{mg})$ in DMF- $d_{7}(1 \mathrm{~mL})$ were added into NMR tubes by syringe and the tubes were sealed under nitrogen before ${ }^{19} \mathrm{~F}$ NMR analysis. ${ }^{19} \mathrm{~F} T_{2}$ values were determined by the Carr-Purcell-Meiboom-Gill (CPMG) pulse sequence using 32 values of $\tau$, with a minimum value of $0.1 \mathrm{~ms}$ and the maximum value of $0.2 \mathrm{~s}$. The NMR samples were not spun for the measurement. The number of scans was set at 128 . Other parameters were as follows: spectral width $=30 \mathrm{ppm} ; 90^{\circ}$ pulse width $=13.4 \mu \mathrm{s}$; relaxation delay $=1 \mathrm{~s}$; data points $=$ 32768.

\section{Encapsulation of Perfluorinated Compounds}

Encapsulation of perfluorinated compounds (PFMCH, PFO, PFH, PFO-ester, PFHp-ketone, PFO-OH) with S1-S5 was evaluated with ${ }^{19} \mathrm{~F}$ NMR.

PFMCH, PFO, and PFH: In a $6 \mathrm{~mL}$ vial, the guests $(0.2 \mathrm{~mL})$ were respectively added into the solution of a star polymer $(\mathbf{S 1 - S 5}, 70 \mathrm{mg})$ in DMF- $d_{7}(1.4 \mathrm{~mL})$. The mixture was vigorously stirred at room temperature for $24 \mathrm{~h}$. After the emulsion mixture was kept calmly for a few days, 
the solution was separated to two phases. The upper transparent layer containing a guest and a star polymer was analyzed by ${ }^{19} \mathrm{~F}$ NMR.

PFO-ester and PFHp-ketone: In a $6 \mathrm{~mL}$ vial, the guests $(0.2 \mathrm{~mL})$ were respectively added into a solution of a star polymer $(\mathbf{S 3}$ or S5: $50 \mathrm{mg})$ in DMF- $d_{7}(0.8 \mathrm{~mL})$. The dispersed mixture was vigorously stirred at room temperature for $24 \mathrm{~h}$. After the solution was kept calmly for a few hours, the solution was separated to two phases. The upper transparent layer containing a guest and a star polymer was analyzed by ${ }^{19} \mathrm{~F}$ NMR.

PFO-OH: In a $6 \mathrm{~mL}$ vial, a DMF- $d_{7}$ solution of a star polymer (S3 or $\left.\mathbf{S 5}, 50 \mathrm{mg} / \mathrm{mL}, 1.0 \mathrm{~mL}\right)$ was added to PFO-OH (17.2 mg). The homogeneous mixture was stirred at room temperature for $24 \mathrm{~h}$. The solution was then analyzed by ${ }^{19} \mathrm{~F}$ NMR.

\section{Result and Discussion}

\section{Synthesis of Fluorinated Microgel Star Polymers}

Five kinds of fluorinated microgel star polymers (S1-S5) were designed with methacrylates carrying different perfluorinated alkyl pendants $\left(\mathrm{R}_{\mathrm{F}} \mathrm{MA}\right)$ as core-fluorination groups: $1 H, 1 H, 2 H, 2 H$-perfluorohexcyl methacrylate (9FHxMA), $1 H, 1 H, 7 H$-perfluoroheptyl methacrylate (12FHрMA), $1 H, 1 H, 2 H, 2 H$-perfluorooctyl methacrylate

(13FOMA), $1 H, 1 H, 2 H, 2 H$-perfluoro-7-methyloctyl methacrylate (15FMOMA), $1 H, 1 H, 2 H, 2 H$-perfluorodecyl methacrylate (17FDeMA). The fluorous nature of the monomers with $\mathrm{CF}_{3}$ end group would increase with the fluorine numbers in the perfluorinated pendants, while 12FHpMA may have properties distinct from the others because of no $\mathrm{CF}_{3}$ end group.

The star polymers were synthesized by $\mathrm{Ru}(\mathrm{Ind}) \mathrm{Cl}\left(\mathrm{PPh}_{3}\right)_{2} / n-\mathrm{Bu}_{3} \mathrm{~N}$-catalyzed linking reaction of a chlorine-capped PMMA [PMMA-Cl: degree of polymerization $(D P)=\sim 100$ ] with 2,2,3,3,4,4,5,5,6,6,7,7-dodecafluoro-1,8-octanediol dimethacrylate (12FODMA) $(m=$ $\left.[12 \mathrm{FODMA}]_{0} /[\mathrm{PMMA}-\mathrm{Cl}]_{0}=5\right)$ in the presence of $\mathrm{R}_{\mathrm{F}} \mathrm{MA}\left(n=\left[\mathrm{R}_{\mathrm{F}} \mathrm{MA}\right]_{0} /[\mathrm{PMMA}-\mathrm{Cl}]_{0}=10\right)$. MMA was first polymerized with $\mathrm{Ru}(\mathrm{Ind}) \mathrm{Cl}\left(\mathrm{PPh}_{3}\right)_{2} / n-\mathrm{Bu} \mathrm{H}_{3} \mathrm{~N}$ (catalyst) and ethyl-2-chloro-2-phenylacetate (ECPA: chloride initiator) in toluene at $80{ }^{\circ} \mathrm{C}$ for $14 \mathrm{~h}$ (conversion: $48 \%)$ to give well-controlled PMMA-Cl with narrow molecular weight distribution $\left(M_{\mathrm{n}}=12000\right.$, $M_{\mathrm{w}} / M_{\mathrm{n}}=1.13$ ). After the removal of the residual MMA from the reaction vessel (by evaporation in vacuo at $25^{\circ} \mathrm{C}$ ), a toluene solution of 12FODMA and $\mathrm{R}_{\mathrm{F}} \mathrm{MA}$ was then added into the vessel containing the PMMA-Cl and non-volatile ruthenium catalyst under argon. In all cases, the linking reaction of PMMA-Cl efficiently and smoothly proceeded up to over $80 \%$ monomer conversion in $18-23 \mathrm{~h}$ at $80{ }^{\circ} \mathrm{C}$ to provide corresponding fluorinated microgel star polymers with 
high molecular weight (S1-S5) in high yield ( $>70 \%$, by SEC in THF) (Figure 1). Importantly, 12FODMA and $\mathrm{R}_{\mathrm{F}} \mathrm{MA}$ were concurrently consumed during arm-linking process (Figure $\mathrm{S} 1$ ), resulting in random, virtually homogeneous, distribution of the perfluorinated alkyl pendants within microgel cores.

\section{Figure 1}

\section{Figure S1}

After purified by preparative SEC (removing the residues of unreacted arms, a ruthenium catalyst, and monomers), S1-S5 were characterized by multi-angle laser light scattering coupled with SEC (SEC-MALLS) in DMF to determine absolute weight-average molecular weight $\left(M_{\mathrm{w}}\right)$, arm numbers $\left(N_{\mathrm{arm}}\right)$, and radius of gyration $\left(R_{\mathrm{g}}\right): M_{\mathrm{w}}=393000-954000 \mathrm{~g} / \mathrm{mol} ; N_{\mathrm{arm}}=19-42 ; R_{\mathrm{g}}=$ 13 - $21 \mathrm{~nm}$ (Table 1). Uniquely, S1-S4 have almost constant arm numbers $\left(N_{\text {arm }}=\sim 20\right)$, whereas S5 has $N_{\text {arm }}(\sim 40)$ about twice larger than S1-S4. The former corresponds to the fact that $N_{\text {arm }}$, i.e., the efficiency of intermolecular crosslinking, is generally determined by the molar ratio of a linking agent to an arm polymer chain $\left(m=[12 \mathrm{FODMA}]_{0} /[\mathrm{PMMA}-\mathrm{Cl}]_{0}=5\right)$. The latter means that, beyond such a general feature, S5 underwent the intermolecular linking of arm polymers more efficiently than the other star polymers. This is because the strong fluorous properties of the perfluorinated segment of 17FDeMA promote the intermolecular association of intermediates, i.e., block copolymers with dangling olefin and perfluorinated pendants and star polymers with small arm numbers therefrom, during microgel formation process.

\section{Table 1}

The numbers of in-core fluorine atoms $\left(N_{\mathrm{F}}\right)$, in-core $\mathrm{CF}_{3}$ end groups $\left(N_{\mathrm{CF} 3}\right)$, and in-core polyfluorinated groups $\left(N_{\mathrm{RF}}\right)$ were calculated form $N_{\mathrm{arm}}$, the feed ratio of a linking reagent and R $\mathrm{FA}(m$ and $n)$, and their conversion: $N_{\mathrm{F}}=N_{\text {arm }} \times[12 \times m \times($ conv. $/ 100)+($ the number of F in a monomer $) \times n \times($ conv. $/ 100)], N_{\mathrm{CF} 3}=N_{\mathrm{arm}} \times\left(\right.$ the number of $\mathrm{CF}_{3}$ in a monomer $) \times n \times($ conv. $/ 100)$, $N_{\mathrm{RF}}=N_{\text {arm }} \times n \times\left(\right.$ conv./100). As shown in Table 1, these were estimated as $2810-8070\left(N_{\mathrm{F}}\right), 0$ $388\left(N_{\mathrm{CF} 3}\right), 150-343\left(N_{\mathrm{RF}}\right)$. Thus, lots of fluorine atoms and perfluorinated alkyl units were successfully accumulated within microgel cores by this simple arm-linking reaction.

S1-S5 were analyzed by ${ }^{1} \mathrm{H}$ NMR in $\mathrm{CD}_{2} \mathrm{Cl}_{2}$ at $30{ }^{\circ} \mathrm{C}$ (Figure 2). S1-S5 showed broad methylene proton signals of in-core 12FODMA $\left(g, g^{\prime}: 4.6 \mathrm{ppm}\right)$ and corresponding $\mathrm{R}_{\mathrm{F}} \mathrm{MA}(i: 4.6-$ $4.2 \mathrm{ppm}, j: 2.6-2.4 \mathrm{ppm})$ and small olefin protons $(h: 6.2,5.7 \mathrm{ppm})$ in addition to the proton signals for PMMA arms (e: $1.3-0.7 \mathrm{ppm}, d: 2.1-1.4 \mathrm{ppm}, f: 3.7-3.4 \mathrm{ppm})$ and the $a$-end initiator 
fragment ( $a$ : $4.1-4.0 \mathrm{ppm}, b: 3.4 \mathrm{ppm}, c: 7.4-7.2 \mathrm{ppm}$ ). The broad signals for the in-core $\mathrm{R}_{\mathrm{F}} \mathrm{MA}$ importantly support that $\mathrm{R}_{\mathrm{F}} \mathrm{MA}$ is placed within microgels crosslinked with 12FODMA. Calculated from the area ratio of olefin signal $(h)$ to an initiator unit $(c)$, the unreacted pendant olefin of 12FODMA was estimated as about 0.3 unit per a single arm chain: i.e., in all star polymers, over $94 \%$ of the pendant olefin was consumed by intra- and intermolecular crosslinking reaction. Additionally, $\mathbf{S 2}$ quantitatively exhibited a tip proton signal $\left(-\mathrm{CHF}_{2}\right)$ of in-core $12 \mathrm{FHpMA}(k: 6.2-$ $5.8 \mathrm{ppm})$; the area ratio is in good agreement with the content per a single arm chain $(n=10)$.

\section{Figure 2}

To evaluate the properties of the in-core perfluorinated alkyl pendants, S1-S5 were further analyzed by ${ }^{19} \mathrm{~F}$ NMR in $\mathrm{CDCl}_{3}$ at $30{ }^{\circ} \mathrm{C}$ (Figure 3). All of the star polymers exhibited the ${ }^{19} \mathrm{~F}$ signals of the in-core $\mathrm{R}_{\mathrm{F}} \mathrm{MA}$ pendants $(a-f)$, whereas the ${ }^{19} \mathrm{~F}$ signals of the 12FODMA perfluorinated spacer $(A, B)$ were hardly detected. This indicates that $\mathrm{R}_{\mathrm{F}} \mathrm{MA}$ pendants are more thermally mobile than $12 \mathrm{FODMA}$ spacer unit. In particular, the tip $\mathrm{CF}_{3}$ and $\mathrm{CHF}_{2}$ groups of the perfluorinated pendants were the most clearly observed. They were thus used as a probe in analyzing the thermal mobility of in-core perfluorinated pendants below.

\section{Figure 3}

\section{Core-Mobility Analysis by $T_{2}$ Measurements}

Thermal mobility of the in-core perfluorinated pendants was evaluated with ${ }^{19} \mathrm{~F}$ NMR spin-spin relaxation time $\left(T_{2}\right)$ measurements of S1-S5 in DMF- $d_{7}$. It has already found that the perfluorinated pendants in star polymers effectively aggregate within microgel cores via fluorous interaction in DMF. The mobility of the perfluorinated pendants would thus tend to decrease with increasing fluorous nature.

At $30{ }^{\circ} \mathrm{C},{ }^{19} \mathrm{~F} T_{2}$ values of the in-core $\mathrm{CF}_{3}$ or $\mathrm{CHF}_{2}$ groups in $\mathbf{S 1 - S 5}$ were determined as 16 (S1), 20 (S2), 7.0 (S3), 5.4 (S4), and 2.6 (S5) ms (Table 2). The $T_{2}$ values decreased with increasing the fluorine atom numbers of in-core $\mathrm{R}_{\mathrm{F}} \mathrm{MA}$ unit $(\mathbf{S 1}<\mathbf{S 3}<\mathbf{S 4}<\mathbf{S 5})$. This indicates that perfluorinated pendants gradually aggregate each other within microgels to be less mobile as the fluorine numbers increase. S5 comprising 12FODMA and 17FDeMA afforded the most stable fluorous compartment. Importantly, $T_{2}$ for $\mathbf{S 2}$ was much larger than that for $\mathbf{S 3}$ in spite of the almost identical fluorine atom numbers of $\mathrm{R}_{\mathrm{F}} \mathrm{MA}\left(12\right.$ - 13), meaning that $\mathrm{CHF}_{2}$-capped pendants are not so fluorous to freely mobile within $\mathbf{S} 2$ without aggregation. 


\section{Table 2}

Temperature-dependent ${ }^{19} \mathrm{~F} T_{2}$ measurements of S1-S5 were conducted in DMF- $d_{7}$ at the various temperatures of $30,50,70,90$, and $110{ }^{\circ} \mathrm{C}$ (Figure 4). Here, the effects of the in-core $\mathrm{R}_{\mathrm{F}} \mathrm{MA}$ species on the pendant mobility is quantitatively evaluated with the apparent activation energy $\left(E_{\mathrm{ap}}\right)$ for the molecular motion that is obtained from Arrhenius plots of $T_{2}$ (temperature-dependence of $T_{2}$ ). $\quad T_{2}$ is proportional to reciprocal of correlation time of dynamics $\left(\tau_{\mathrm{c}}\right)$ according to the following equation: $T_{2} \propto \tau_{\mathrm{c}}{ }^{-1}=\mathrm{A} \exp \left(-E_{\mathrm{ap}} / R T\right)(1)$, where $R$ and $T$ means gas constant and temperature.

\section{Figure 4}

Figure 4 shows plots of logarithmic $T_{2}$ for S1-S5 against inverse temperature (1/T) in DMF- $d_{7}$. All of $\ln T_{2}$ values were inversely proportional to $1 / T$, demonstrating that the mobility of their $\mathrm{CF}_{3}$ or $\mathrm{CHF}_{2}$ groups obeys Arrhenius equation (eq. 1). $\quad E_{\text {ap }}$ was estimated from the slope of the plots as follows: $E_{\text {ap }}=33$ (S1), 26 (S2), 39 (S3), 44 (S4), and 44 (S5) kJ/mol (Table 2). This revealed that activation energy $\left(E_{\mathrm{ap}}\right)$ also increased with the physical association of perfluorinated pendants by fluorous interaction within the cores; $\mathbf{S 5}$ had the largest $E_{\text {ap }}$ to form most stable fluorous compartment.

\section{Guest Encapsulation and Stimuli-Responsive Release}

Encapsulation of perfluorinated guest molecules was investigated with fluorinated microgel star polymers (S1-S5) in DMF- $d_{7}$. Discussion was especially focused on encapsulation efficiency, fluorous interaction, and host/guest mobility, dependent on the in-core perfluorinated units. The guest encapsulation would be enhanced with increasing the fluorous interaction between the in-core perfluorinated pendants and a guest molecule.

PFMCH Encapsulation. Perfluoromethylcyclohexane (PFMCH) was first employed as a guest molecule that is fluorous, immiscible with common organic solvents (e.g., DMF) and water., ${ }^{8,9}$ PFMCH was mixed and solubilized with S1-S5 in DMF- $d_{7}$ at $25^{\circ} \mathrm{C}$ for $24 \mathrm{~h}$, resulting in emulsion mixtures. After the phase separation, the transparent supernatant was analyzed by ${ }^{19} \mathrm{~F}$ NMR at 30 ${ }^{\circ} \mathrm{C}$ (Figure 5). The $\mathrm{CF}_{3}$ multiplet signal of PFMCH alone ( $\left.a:-70.25 \mathrm{ppm}\right)$ turned broad and shifted to upfield in the presence of $\mathbf{S 1}\left(a^{\prime}:-70.35 \mathrm{ppm}\right), \mathbf{S 3}\left(a^{\prime}:-70.6 \mathrm{ppm}\right), \mathbf{S 4}\left(a^{\prime}:-70.7 \mathrm{ppm}\right)$, and $\mathbf{S 5}$ ( $\left.a^{\prime}:-70.95 \mathrm{ppm}\right)$. This demonstrated that S1, S3-S5 efficiently interacted with PFMCH to enclose the guest within their fluorous microgels. Particularly, S5 with long perfluorinated alkyl units ( $1 H, 1 H, 2 H, 2 H$-perfluorodecyl) led to the broadest fluorine signal of PFMCH (Figure $5 f$ ). In the 
presence of S2, the $\mathrm{CF}_{3}$ signal of PFMCH was in turn still multiplet despite of the upfield shift ( $a^{\prime}$ : $-70.45 \mathrm{ppm})$. This indicates that $\mathbf{S 2}$ actually solubilized PFMCH but does not so efficiently enclose it within the core owing to the less fluorous properties of the in-core 12FHpMA bearing a $-\mathrm{CHF}_{2}$ end group.

\section{Figure 5}

The mobility of PFMCH enclosed within S1-S5 was evaluated with ${ }^{19} \mathrm{~F} T_{2}$ measurements of the guest $\mathrm{CF}_{3}$ group (Table 3). The $T_{2}$ values were dependent on the star polymer species: $T_{2}=$ 177 (S1), 472 (S2), 136 (S3), and 69 (S4 and S5) ms. All of the values were much shorter than $T_{2}$ for PFMCH alone $\left(3150 \mathrm{~ms}\right.$, in $\left.\mathrm{CDCl}_{3}\right)$. In particular, $\mathbf{S 4}$ and $\mathbf{S 5}$ effectively shortened $T_{2}$ for PFMCH, i.e., reduced the guest mobility, indicating that $\mathbf{S 4}$ and $\mathbf{S 5}$ with long perfluorinated pendants tightly capture PFMCH within the cores. Among S1-S5, S2 in turn gave relatively long $T_{2}$ for PFMCH. This clearly demonstrates that $\mathrm{PFMCH}$ is not so tightly bound with the 12FHpMA-based microgel owing to the less fluorous properties. The mobility for PFMCH $\left(T_{2}\right.$ : S5 $\sim \mathbf{S 4}<\mathbf{S 3}<\mathbf{S 1}<\mathbf{S 2})$ decreased with increasing $E_{\text {ap }}$ for the in-core perfluorinated pendants $\left(E_{\mathrm{ap}}\right.$ : $\mathbf{S 5} \sim \mathbf{S 4}>\mathbf{S 3}>\mathbf{S 1}>\mathbf{S 2}$, Table 2). In contrast, the mobility of the in-core perfluorinated pendants in star polymers ( $T_{2}$ values for the $\mathrm{CF}_{3}$ or $\mathrm{CHF}_{2}$ groups) was almost independent of a PFMCH guest molecule (Table 2 and 3).

\section{Table 3}

The encapsulation efficiency of PFMCH was quantitatively evaluated with the number of PFMCH solubilized in a single star polymer $\left(N_{\text {guest }}\right)$. $\quad N_{\text {guest }}$ was calculated from the area ratio of the guest $\mathrm{CF}_{3}$ signal (Figure 5) to the $\mathrm{CF}_{3}$ or $\mathrm{CF}_{2} \mathrm{H}$ signals of the in-core perfluorinated pendants by ${ }^{19} \mathrm{~F}$ NMR, assuming that all of their ${ }^{19} \mathrm{~F}$ signals were quantitatively observed: $N_{\text {guest }}=40($ S1), 80 (S2), 106 (S3), 250 (S4), and 260 (S5). The number of PFMCH bound by one $\mathrm{R}_{\mathrm{F}} \mathrm{MA}$ unit $\left(N_{\text {guest }} / N_{\mathrm{RF}}\right)$ was thus determined to be 0.24 (S1), 0.54 (S2), 0.64 (S3), 1.29 (S4), and 0.77 (S5) (Figure 6). This result reveals that the encapsulation efficiency is not only enhanced with the total fluorine atom numbers $(\mathbf{S 1}<\mathbf{S 2}<\mathbf{S 3}<\mathbf{S 5})$ but also with the tip $\mathrm{CF}_{3}$ numbers $(\mathbf{S 3}<\mathbf{S 4})$. Actually, S4 (1.29) was twice more effective per one $\mathrm{R}_{\mathrm{F}} \mathrm{MA}$ unit than $\mathbf{S 3}$ (0.64), while the efficiency of $\mathbf{S 4}$ per one $\mathrm{CF}_{3}$ group was almost identical with that of $\mathbf{S 3}$. Thus, the accumulation of $\mathrm{CF}_{3}$ group in microgels is also quite important for the encapsulation of large number of perfluorinated guests.

\section{Figure 6}


Various Guest Molecules. Next, S3 and S5 were applied to the encapsulation of various perfluorinated compounds including perflurooctane (PFO), perfluorohexane (PFH), methyl perfluorooctanoate (PFO-ester), methyl perfluoroheptyl ketone (PFHp-ketone), and $1 H, 1 H$-perfluoro-1-octanol (PFO-OH). These guests were mixed with $\mathbf{S 3}$ or $\mathbf{S 5}$ in DMF- $d_{7}$ for 24 h. PFO, PFH, PFO-ester, and PFO-ketone gave heterogeneous mixture (PFO and PFH: emulsion, PFO-ester, and PFO-ketone: dispersion), whereas PFO-OH did homogenous counterpart. The phase-separated, transparent supernatants or the homogenenous solution were analyzed by ${ }^{19} \mathrm{~F}$ NMR (Figure 7).

\section{Figure 7}

In the presence of $\mathbf{S 3}$, the $\mathrm{CF}_{3}$ peaks for $\mathrm{PFO}, \mathrm{PFH}$, and $\mathrm{PFO}$-ester shifted to upfield and broadened, while those for PFHp-ketone and PFO-OH were still observed as triplet signals. This indicates that perfluorinated alkanes and the ester derivative are bound within $\mathbf{S 3}$ core via fluorous interaction, whereas perfluorinated alkanes with ketone and alcohol functionality are freely mobile within and/or around $\mathbf{S 3}$ because of their less fluorous properties originating from the polar functional groups (carbonyl, hydroxyl). In contrast, with the more fluorous core, $\mathbf{S 5}$ made the $\mathrm{CF}_{3}$ signal of PFHp-ketone broad, indicating the successful recognition of the guest (Figure 7d). Less recognition for PFO-OH with both $\mathbf{S 3}$ and $\mathbf{S 5}$ would be due to the originally high affinity of PFO-OH with DMF. These results reveal that fluorinated microgel star polymers can also encapsulate perfluorinated alkane derivatives with ester or ketone functional groups by enhancing the fluorous interaction.

Thermoresponsive Reversible Encapsulation and Release. We have already found that perfluorinated compounds can be released from perfluorinated microgel star polymers by the addition of good solvents for the guest compounds. ${ }^{8,9}$ Here, we examined temperature-responsive, reversible encapsulation and release of PFMCH with $\mathbf{S 3}$ in DMF- $d_{7}$ (Figure 8). PFMCH is known to have thermoresponsive solubility against organic solvents: i.e., the compound is miscible with them upon heating owing to reduced fluorous properties. ${ }^{2}$ As already confirmed by ${ }^{19} \mathrm{~F}$ NMR (up-field shift and broadening of $\mathrm{CF}_{3}: a^{\prime}-70.6 \mathrm{ppm}$, Figure 8b), $\mathbf{S 3}$ efficiently interacted with $\mathrm{PFMCH}$ in DMF- $d_{7}$ at $30{ }^{\circ} \mathrm{C}$. Importantly, the correlation peak between PFMCH $\mathrm{CF}_{3}$ group $(a)$ and the $\mathrm{CF}_{3}$ of the in-core perfluorinated unit $(b)$ was clearly observed in ${ }^{19} \mathrm{~F}$ nuclear Overhauser effect (NOE) difference spectrum (Figure 8c). This strongly supports that PFMCH is enclosed within $\mathbf{S 3}$ core at $30{ }^{\circ} \mathrm{C}$. Upon heating the solution to $60{ }^{\circ} \mathrm{C}$, the $\mathrm{CF}_{3}$ signal of PFMCH shifted to the original position ( $a$ : $-70.3 \mathrm{ppm}$ ) and turned multiplet (Figure 8d); the NOE signal between PFMCH and in-core perfluorinated pendants also disappeared (Figure 8e). Thus, PFMCH was 
released from the core at $60{ }^{\circ} \mathrm{C}$. This is due to the reduced fluorophilicity of PFMCH upon heating. By cooling the solution to $30{ }^{\circ} \mathrm{C}$, the released $\mathrm{PFMCH}$ was again encapsulated into $\mathbf{S 3}$ core, as confirmed by ${ }^{19}$ F NMR (Figure 8f). Similarly to S3, S5 also showed such a thermoresponsive release of PFMCH upon heating. Thus, independently of the in-core fluorophilicity, fluorinated microgel star polymers, $\mathbf{S 3}$ and $\mathbf{S 5}$, successfully realized the temperature-dependent, reversible encapsulation and release of PFMCH in DMF.

\section{Figure 8}

\section{Conclusions}

We successfully created fluorinated microgel star polymers as fluorous nanocapsules for the encapsulation and release of polyfluorinated guest compounds. Five kinds of star polymers with different fluorous cores were efficiently prepared in high yield via the ruthenium-catalyzed linking reaction of PMMA-Cl with a perfluorinated linking agent (12FODMA) in the presence of perfluorinated alkyl monomers $\left(\mathrm{R}_{\mathrm{F}} \mathrm{MA}\right)$; $\mathrm{R}_{\mathrm{F}} \mathrm{MA}$ consists of different perfluorinated pendants (the number of the carbon and fluorine atoms and $\mathrm{CF}_{3}$ group, the tip structure of the pendants: $\mathrm{CF}_{3}$ vs.

$\mathrm{CHF}_{2}$ ). ${ }^{19} \mathrm{~F} \quad T_{2}$ measurements of star polymers revealed that the mobility of the in-core perfluorinated units decreased with increasing the fluorous properties: i.e., the number of fluorine substitution and $\mathrm{CF}_{3}$ group in $\mathrm{R}_{\mathrm{F}} \mathrm{MA}$ unit. Core-fluorinated star polymers efficiently encapsulated perfluorinated alkanes and the derivatives with ester or ketone functionality in DMF. The efficiency increased with increasing the number of fluorine substitution and $\mathrm{CF}_{3}$ group in the in-core $\mathrm{R}_{\mathrm{F}} \mathrm{MA}$ units. Additionally, a fluorinated star polymer successfully afforded the reversible encapsulation and release of a perfluorinated guest by changing temperature. Thus, star polymers developed herein would be useful as temperature-responsive fluorous nanocapsules for the encapsulation, separation, and delivery of various perfluorinated compounds.

\section{Acknowledgements}

This research was supported by the Ministry of Education, Science, Sports and Culture through Grants-in-Aid for Scientific Research (A: 24245026, C: 26410134) and Young Scientist (B: 24750104), for which T.T. is grateful. Y.K. is grateful to the Japan Society for the Promotion of Sciences (JSPS) for a Grant-in-Aid for JSPS Research Fellows (DC1: 24-6140). 


\section{References}

1 J. G. Riess, Tetrahedron, 2002, 58, 4113-4131; M. P. Krafft, Adv. Drug Delivery Rev., 2007, 47, 209-228; M. P. Krafft, J. G. Riess, Chem. Rev. 2009, 109, 1714-1792.

2 I. T. Horváth, J. Rábai, Science, 1994, 266, 72-75.

3 A. Studer, S. Hadida, R. Ferritto, S.-Y. Kim, P. Jeger, P. Wipf, D. P. Curran, Science 1997, 275, 823-826.

4 J. Yoshida, K. Itami, Chem. Rev. 2002, 102, 3693-3716.

5 B. Améduri, Macromolecules 2010, 43, 10163-10184.

6 A. B. Lindstrom, M. J. Strynar, E. L. Libelo, Environ. Sci. Technol. 2011, 45, 7954-7961.

7 D. P. Curran, M. K. Sinha, K. Zhang, J. J. Sabatini, D.-H. Cho, Nat. Chem. 2012, 4, 124-129.

8 Y. Koda, T. Terashima, A. Nomura, M. Ouchi, M. Sawamoto, Macromolecules 2011, 44, 4574-4578.

9 Y. Koda, T. Terashima, M. Sawamoto, J. Am. Chem. Soc., 2014, 136, 15742-15748.

10 Y. Koda, T. Terashima, M. Sawamoto, H. D. Maynard, Polym. Chem., 2015, 6, 240-247.

11 Z. Li, E. Kesselman, Y. Talmon, M. A. Hillmyer, T. P. Lodge, Science 2004, 306, 98-101.

12 T. P. Lodge, A. Rasdai, Z. Li, M. A. Hillmyer, J. Am. Chem. Soc., 2005, 127, 17608-17609.

13 K. Matsumoto, H. Mazaki, H. Matsuoka, Macromolecules 2004, 37, 2256-2267.

14 S. Sato, J. Iida, K. Suzuki, M. Kawano, T. Ozeki, M. Fujita, Science 2006, 313, 1273-1276.

15 K. Honda, M. Morita, O. Sakata, S. Sasaki, A. Takahara, Macromolecules 2010, 43, 454-460.

16 A. Blencowe, J. F. Tan, T. K. Goh, G. G. Qiao, Polymer 2009, 50, 5-32; H. Gao, K. Matyjaszewski, Prog. Polym. Sci. 2009, 34, 317-350; H. Gao, Macromol. Rapid Commun. 2012, 33, $722-734$.

17 T. Terashima, M. Sawamoto, ACS Symp. Ser. 2012, 1101, 65-80; T. Terashima, Kobunshi Ronbunshu 2013, 70, 432-448; T. Terashima, Polym. J. 2014, 46, 664-673.

18 K.-Y. Baek, M. Kamigaito, M. Sawamoto, Macromolecules 2001, 34, 215-221.

19 H. Gao, K. Matyjaszewski, Macromolecules 2006, 39, 7216-7223.

20 T. Shibata, S. Kanaoka, S. Aoshima, J. Am. Chem. Soc. 2006, 128, 7497-7504.

21 T. Terashima, R. Motokawa, S. Koizumi, M. Sawamoto, M. Kamigaito, T. Ando, T. Hashimoto, Macromolecules 2010, 43, 8218-8232.

22 T. Terashima, S. Nishioka, Y. Koda, M. Takenaka, M. Sawamoto, J. Am. Chem. Soc., 2014, 136, 10254-10257.

23 N. Nishiyama, K. Kataoka, Adv. Polym. Sci. 2006, 193, 67-101; S. F. M. van Dongen, H.-P. M. de Hoog, R. J. R. W. Peters, M. Nallani, R. J. M. Nolte, J. C. M. van Hest, Chem. Rev. 2009, 109, 6212-6274; A, V. Kabanov, S. V. Vinogradov, Angew. Chem. Int. Ed. 2009, 48, 5418-5429; M. 
Elsabahy, K. L. Wooley, J. Polym. Sci., Part A: Polym. Chem. 2012, 50, 1869-1880; A. Walther, A. H. E. Müller, Chem. Rev. 2013, 113, 5019-5261.

24 K.-Y. Baek, M. Kamigaito, M. Sawamoto, Macromolecules 2001, 34, 7629-7635; K.-Y. Baek, M. Kamigaito, M. Sawamoto, Macromolecules 2002, 35, 1493-1498.

25 T. Terashima, M. Kamigaito, K.-Y. Baek, T. Ando, M. Sawamoto, J. Am. Chem. Soc. 2003, 125, 5288-5289; T. Terashima, M. Ouchi, T. Ando, M. Kamigaito, M. Sawamoto, J. Polym. Sci., Part A: Polym. Chem. 2006, 44, 4966-4980; T. Terashima, M. Ouchi, T. Ando, M. Kamigaito, M. Sawamoto, Macromolecules 2007, 40, 3581-3588.

26 T. Terashima, M. Ouchi, T. Ando, M. Sawamoto, J. Polym. Sci., Part A: Polym. Chem. 2011, 49, 1061-1069; T. Terashima, M. Ouchi, T. Ando, M. Sawamoto, J. Polym. Sci., Part A: Polym. Chem. 2010, 48, 373-379; T. Terashima, M. Ouchi, T. Ando, M. Sawamoto, Polym. J. 2011, 43, 770-777.

27 T. Terashima, A. Nomura, M. Ito, M. Ouchi, M. Sawamoto, Angew. Chem. Int. Ed. 2011, 50, 7892-7895; T. Terashima, A. Nomura, M. Ouchi, M. Sawamoto, Macromol. Rapid Commun. $2012,33,833-841$.

28 K. Fukae, T. Terashima, M. Sawamoto, Macromolecules 2012, 45, 3377-3386.

29 B. Helms, S. J. Guillaudeu, Y. Xie, M. McMurdo, C. J. Hawker, J. M. J. Fréchet, Angew. Chem. Int. Ed. 2005, 44, 6384-6387; Y. Chi, S. T. Scroggins, J. M. J. Fréchet, J. Am. Chem. Soc. 2008, 130, 6322-6323.

30 M. Ouchi, T. Terashima, M. Sawamoto, Acc. Chem. Res. 2008, 41, 1120-1132; M. Ouchi, T. Terashima, M. Sawamoto, Chem. Rev. 2009, 109, 4963-5050.

31 N. Tsarevsky, K. Matyjaszewski, Chem. Rev. 2007, 107, 2270-2299; K. Matyjaszewski, N. V. Tsarevsky, Nat. Chem. 2009, 1, 276-288; K. Matyjaszewski, Macromolecules 2012, 45, 4015-4039.

32 C. J. Hawker, A. W. Bosman, E. Harth, Chem. Rev. 2001, 101, 3661-3688.

33 S. Aoshima, S. Kanaoka, Chem. Rev. 2009, 109, 5245-5287.

34 H. L. Hsieh, R. P. Quirk, Anionic polymerization: Principles and practical applications. Marcel Dekker, Inc. New York, 1996. 
(a)
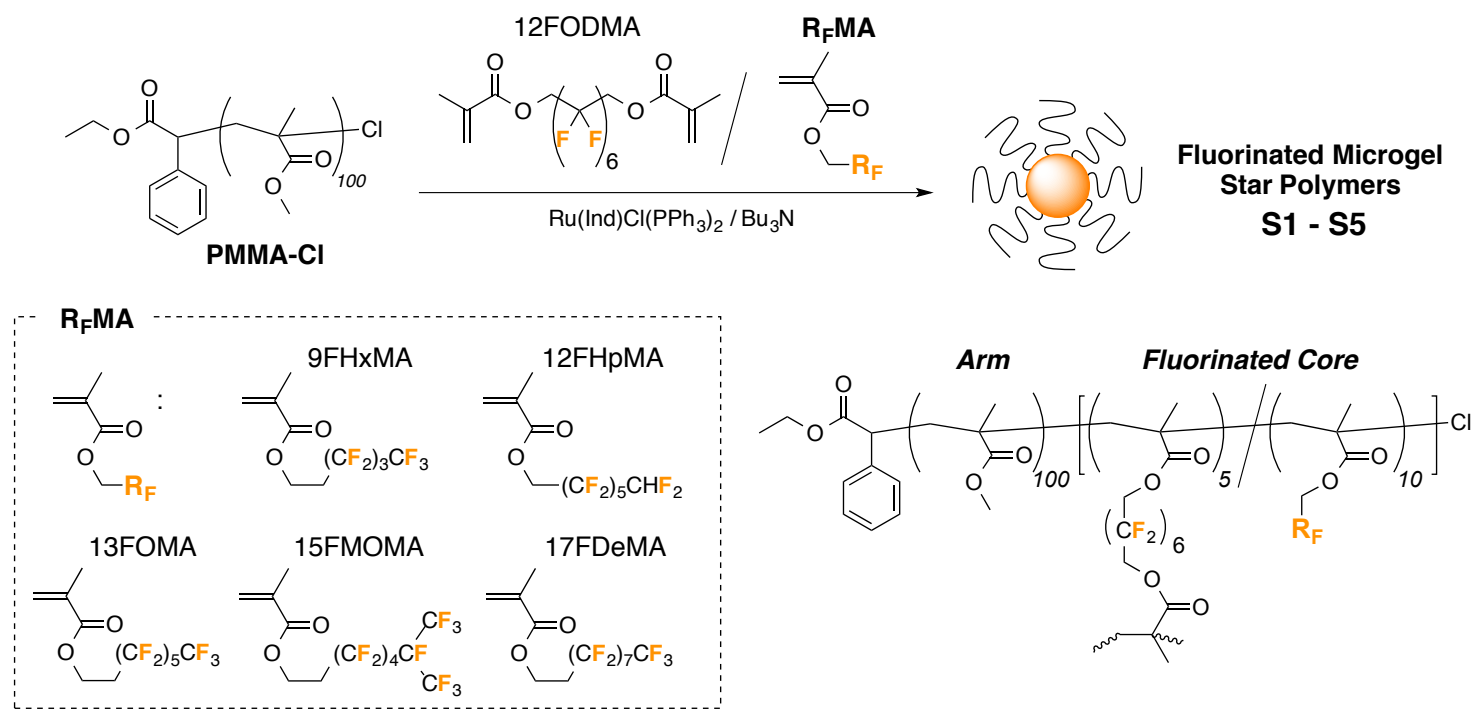

(b)

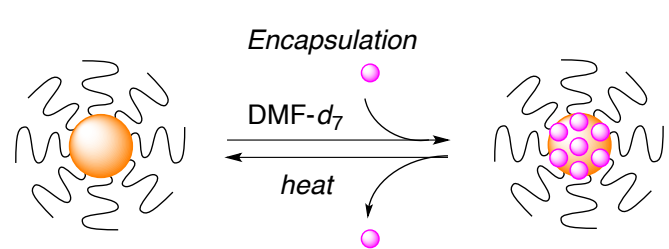

Fluorinated Microgel Star Polymers

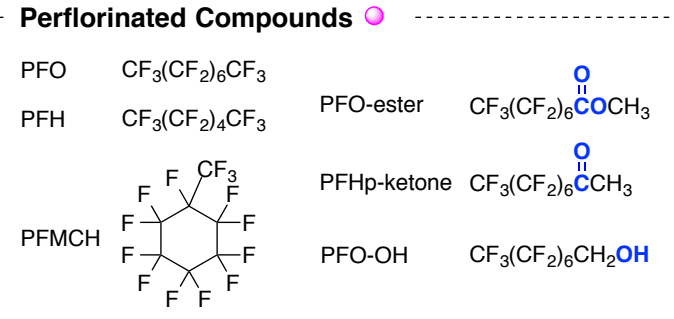

Scheme 1. (a) Synthesis of fluorinated microgel star polymers (S1-S5) via ruthenium-catalyzed living radical polymerization and (b) encapsulation and release of perfluorinated compounds with fluorinated star polymers. 
Table 1. Characterization of Fluorinated Microgel Star Polymers ${ }^{a}$

\begin{tabular}{|c|c|c|c|c|c|c|c|c|c|c|c|c|}
\hline Code & $\mathrm{R}_{\mathrm{F}} \mathrm{MA}$ & $\begin{array}{l}\text { Time } \\
{[\mathrm{h}]}\end{array}$ & $\begin{array}{c}\text { Conversion }^{b} \\
\left(12 \mathrm{FODMA} / \mathrm{R}_{\mathrm{F}} \mathrm{MA}\right) \%\end{array}$ & $\begin{array}{c}\text { Yield }^{c} \\
\%\end{array}$ & $\begin{array}{c}M_{\mathrm{w}}{ }^{d} \\
(\mathrm{SEC})\end{array}$ & $\begin{array}{r}M_{\mathrm{w}} / M_{\mathrm{n}}{ }^{d} \\
(\mathrm{SEC})\end{array}$ & $\begin{array}{c}M_{\mathrm{w}}{ }^{e} \\
(\text { MALLS) }\end{array}$ & $N_{\text {arm }}^{f}$ & $N_{\mathrm{F}}^{g}$ & $N_{\mathrm{CF} 3}^{h}$ & $N_{\mathrm{RF}}^{i}$ & $\begin{array}{c}R_{\mathrm{g}}^{e} \\
{[\mathrm{~nm}]}\end{array}$ \\
\hline S1 & 9FHxMA & 18 & $90 / 79$ & 78 & 141000 & 1.24 & 461000 & 23 & 2970 & 177 & 177 & 13 \\
\hline S2 & 12FHрMA & 18 & 8 & 77 & 141000 & 1.24 & 399000 & 19 & 2810 & 0 & 150 & 23 \\
\hline S3 & 13FOMA & 23 & $89 / 79$ & 71 & 155000 & 1.20 & 393000 & 21 & 3260 & 165 & 165 & 21 \\
\hline S4 & 15FMOMA & 19 & $89 / 79$ & 76 & 144000 & 1.22 & 509000 & 25 & 4220 & 388 & 194 & 18 \\
\hline S5 & 17FDeMA & 18 & $90 / 82$ & 73 & 200000 & 1.17 & 954000 & 42 & 8070 & 343 & 343 & 21 \\
\hline
\end{tabular}

${ }^{a}$ S1-S5 was prepared by ruthenium-catalyzed linking reaction of PMMA-Cl $\left(\right.$ S1, S2, S4, S5: $M_{\mathrm{n}}=12000, M_{\mathrm{w}} / M_{\mathrm{n}}=$ 1.13; S3: $\left.\quad M_{\mathrm{n}}=10500, \quad M_{\mathrm{w}} / M_{\mathrm{n}}=1.14\right)$ with 12FODMA and RA: $[\mathrm{PMMA}-\mathrm{Cl}]_{0} /[12 \mathrm{FODMA}]_{0} /\left[\mathrm{R}_{\mathrm{F}} \mathrm{MA}\right]_{0} /\left[\mathrm{Ru}(\mathrm{Ind}) \mathrm{Cl}\left(\mathrm{PPh}_{3}\right)_{2}\right]_{0} /\left[n-\mathrm{Bu}_{3} \mathrm{~N}\right]_{0}=17 / 85 / 170 / 1.7 / 17 \mathrm{mM}$ in toluene at $80{ }^{\circ} \mathrm{C} ; m=$ $[12 \mathrm{FODMA}]_{0} /[\mathrm{PMMA}-\mathrm{Cl}]_{0}=5 ; n=\left[\mathrm{R}_{\mathrm{F}} \mathrm{MA}\right]_{0} /[\mathrm{PMMA}-\mathrm{Cl}]_{0}=10$.

${ }^{b}$ Monomer conversion determined by ${ }^{1} \mathrm{H}$ NMR with internal standard (tetralin). S2: total monomer conversion.

${ }^{c}$ Yield of star polymers in products, calculated from the SEC curve area ratio.

${ }^{d}$ Weight average molecular weight $\left(M_{\mathrm{w}}\right)$ and molecular weight distribution $\left(M_{\mathrm{w}} / M_{\mathrm{n}}\right)$ determined by SEC in THF with PMMA calibration (S1-S5: purified by preparative SEC).

${ }^{e}$ Absolute weight average molecular weight $\left[M_{\mathrm{w}}\right.$ (MALLS)] and radius of gyration $\left(R_{\mathrm{g}}\right)$ determined by SEC-MALLS in DMF (10 mM LiBr).

${ }^{f}$ Arm numbers per a star polymer: $N_{\text {arm }}=$ (weight fraction of arm polymers) $\times M_{\mathrm{w}}\left(\right.$ MALLS) $/ M_{\mathrm{w} \text {,arm }}$ (SEC).

${ }^{g}$ Fluorine atom numbers in a polymer: $N_{\mathrm{F}}=N_{\mathrm{arm}} \times\{12 \times m \times($ conv. $/ 100)+($ the number of $\mathrm{F}$ in a monomer $) \times n \times$ (conv./100)\}.

${ }^{h}$ Pendant $\mathrm{CF}_{3}$ group numbers in a polymer: $N_{\mathrm{CF} 3}=N_{\text {arm }} \times\left(\right.$ the number of $\mathrm{CF}_{3}$ in a monomer $) \times n \times($ conv. $\left./ 100)\right\}$.

${ }^{i}$ Pendant $\mathrm{R}_{\mathrm{F}}$ group numbers in a polymer: $N_{\mathrm{RF}}=N_{\mathrm{arm}} \times n \times($ conv. $\left./ 100)\right\}$. 


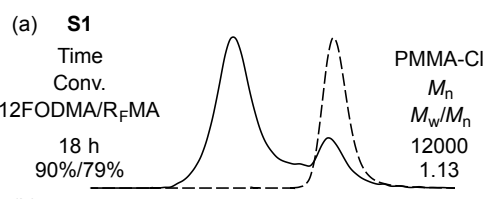

(b)

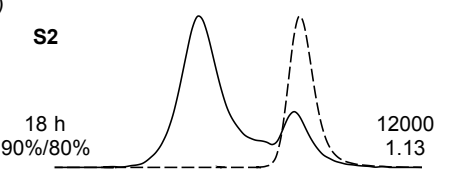

(c)

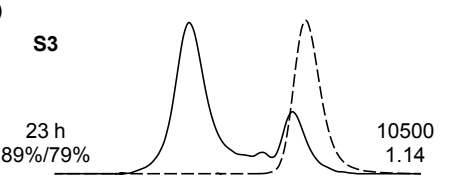

$(\mathrm{d})$
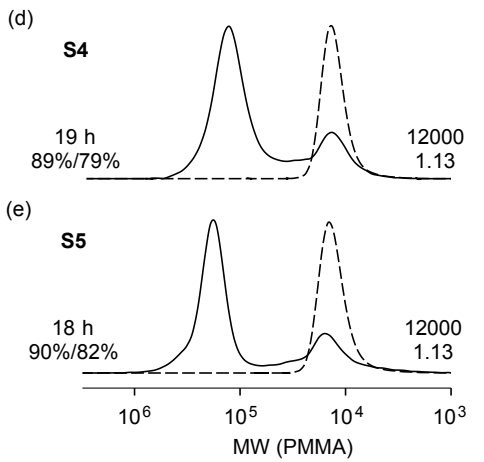

Figure 1. SEC curves of (a) S1, (b) S2, (c) S3, (d) S4, and (e) S5 obtained from $\mathrm{Ru}(\mathrm{Ind}) \mathrm{Cl}\left(\mathrm{PPh}_{3}\right)_{2} / \mathrm{Bu}_{3} \mathrm{~N}$-catalyzed linking reaction of PMMA-Cl with $12 \mathrm{FODMA}$ and $\mathrm{R}_{\mathrm{F}} \mathrm{MA}$ (a: 9FHxMA, b: 12FHpMA, c: 13FOMA, d: 15FMOMA, e: 17FDeMA) in toluene at $80{ }^{\circ} \mathrm{C}$. Monomer feed ratio: $[\mathrm{PMMA}-\mathrm{Cl}]_{0} /[12 \mathrm{FODMA}]_{0} /\left[\mathrm{R}_{\mathrm{F}} \mathrm{MA}\right]_{0}=1 / 5 / 10$. 


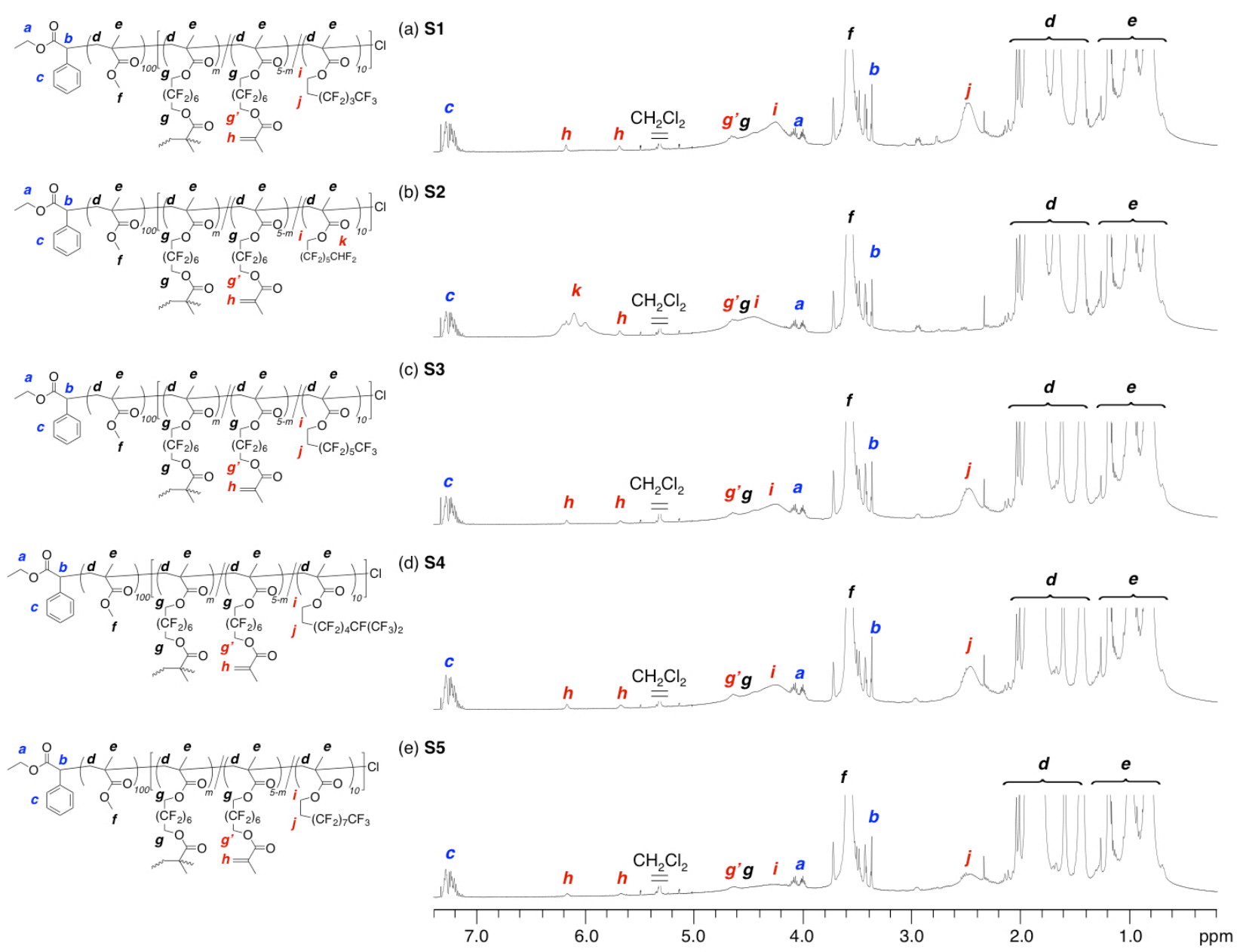

Figure 2. ${ }^{1} \mathrm{H}$ NMR (500 MHz) spectra of (a) S1, (b) S2, (c) S3, (d) S4, and (e) S5 ([star] $=50$ $\mathrm{mg} / \mathrm{mL})$ in $\mathrm{CD}_{2} \mathrm{Cl}_{2}$ at $30{ }^{\circ} \mathrm{C}$. 
(a)

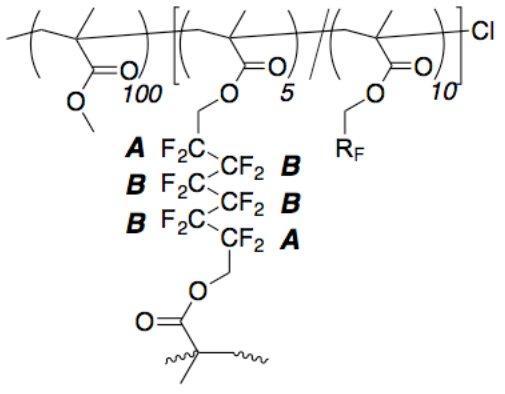

(b)
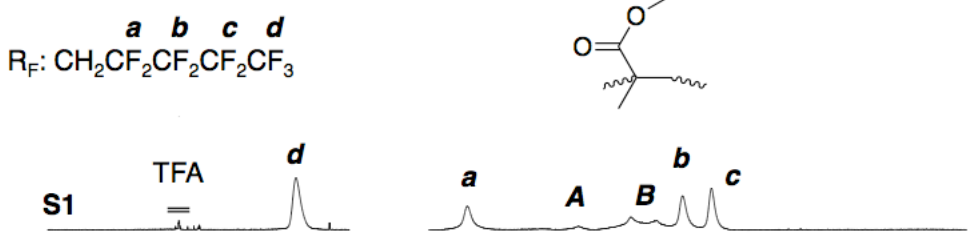

$$
\underset{\mathrm{CF}_{2}\left(\mathrm{CF}_{2}\right)_{3} \mathrm{CF}_{2} \mathrm{CHF}_{2}}{\boldsymbol{a}}
$$

(c)
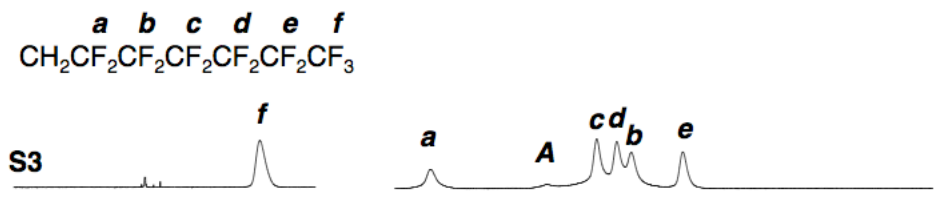

(d)
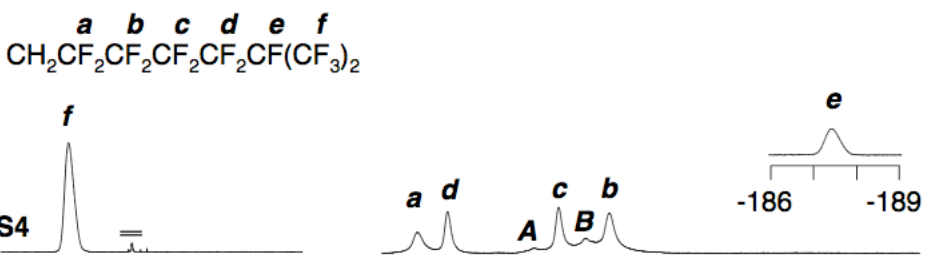

(e)
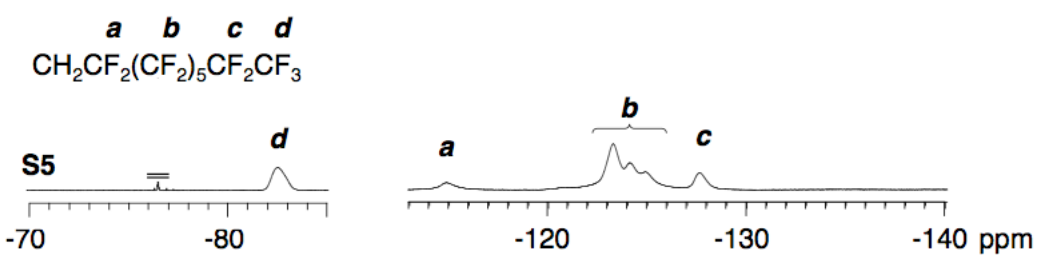

Figure 3. ${ }^{19} \mathrm{~F}$ NMR (470 MHz) spectra of (a) $\mathbf{S 1}$, (b) $\mathbf{S 2}$, (c) $\mathbf{S 3}$, (d) $\mathbf{S 4}$, and (e) $\mathbf{S 5}$ ([star $]=50$ $\mathrm{mg} / \mathrm{mL}$ ) in $\mathrm{CDCl}_{3}$ at $30{ }^{\circ} \mathrm{C}$ (TFA: trifluoroacetic acid, $\delta=-76.5 \mathrm{ppm}$ ). 
Table 2. $T_{2}$ and $E_{\text {ap }}$ of In-Core Perfluorinated Pendants in Star Polymers

\begin{tabular}{cccc}
\hline Entry & Polymer & $\begin{array}{c}T_{2}[\mathrm{~ms}] \\
\left(30^{\circ} \mathrm{C}\right)\end{array}$ & $\begin{array}{c}E_{\mathrm{ap}}{ }^{b} \\
{[\mathrm{~kJ} / \mathrm{mol}]}\end{array}$ \\
\hline 1 & $\mathbf{S 1}$ & 16 & 33 \\
2 & $\mathbf{S 2}$ & 20 & 26 \\
3 & $\mathbf{S 3}$ & 7.0 & 39 \\
4 & $\mathbf{S 4}$ & 5.4 & 44 \\
5 & $\mathbf{S 5}$ & 2.6 & 44 \\
\hline
\end{tabular}

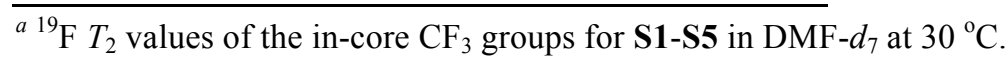

${ }^{b}$ Apparent activation energy for molecular motion $\left(E_{\text {ap }}\right)$ : determined from the slope of Arrhenius plots of the ${ }^{19} \mathrm{~F} T_{2}$ values for the in-core $\mathrm{CF}_{3}$ groups for $\mathbf{S 1 - S 5}$ in DMF- $d_{7}$. 


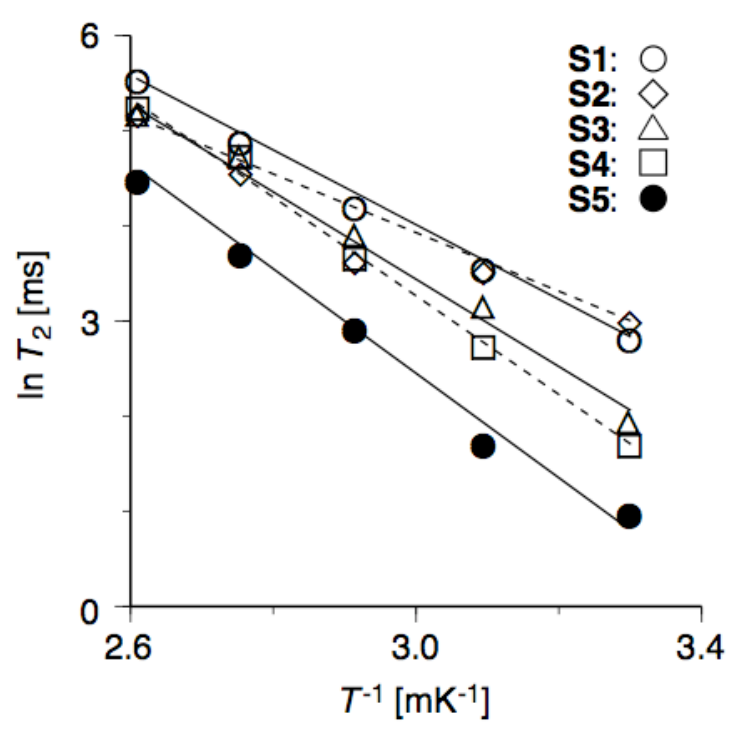

Figure 4. Arrhenius plots of ${ }^{19} \mathrm{~F} T_{2}$ values of the terminal $\mathrm{CF}_{3}$ or $\mathrm{CHF}_{2}$ groups for $\mathbf{S} \mathbf{1}$ (open circle), S2 (open rhombus), S3 (open triangle), S4 (open square), and S5 (filled circle) determined in DMF $-d_{7}$ at $30,50,70,90$, and $110^{\circ} \mathrm{C}$. 
(a)

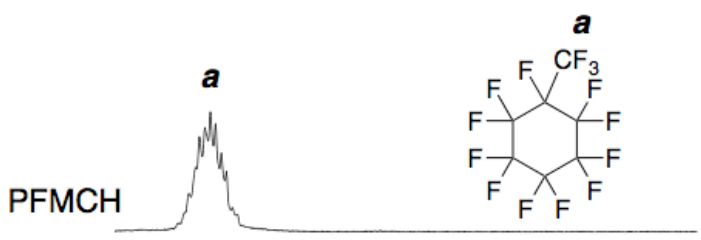

(b)

$$
a^{\prime}
$$

$\mathrm{PFMCH} / \mathrm{S} 1$

(c)

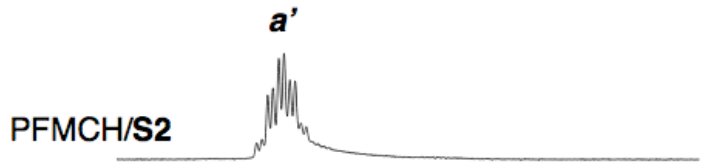

(d)

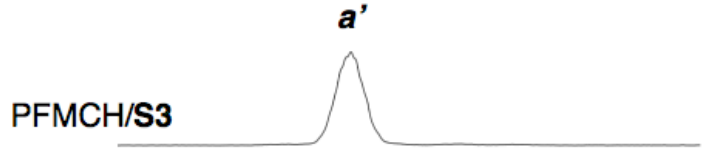

(e)

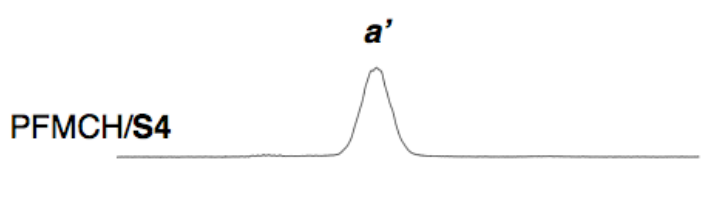

(f)

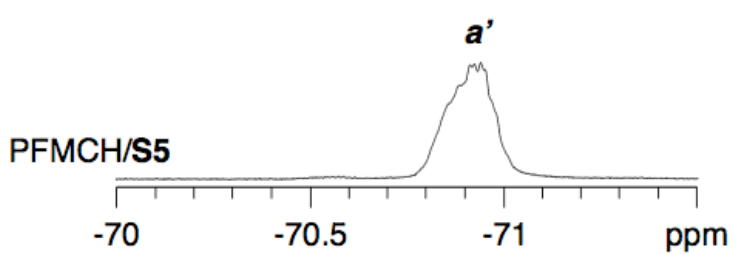

Figure 5. ${ }^{19} \mathrm{~F}$ NMR (470 MHz) spectra of (a) PFMCH alone and (b-f) PFMCH with S1-S5 (b: S1, c: S2, d: S3, e: S4, f: S5): [S1-S5] $=50 \mathrm{mg} / \mathrm{mL}$ in DMF- $d_{7}$ at $30{ }^{\circ} \mathrm{C}$. 
Table 3. Encapsulation of PFMCH into Fluorinated Microgel Star Polymers

\begin{tabular}{ccccc}
\hline Polymer & $\begin{array}{c}T_{2}(\mathrm{PFMCH})^{a} \\
{[\mathrm{~ms}]}\end{array}$ & $\begin{array}{c}T_{2}(\mathrm{Core})^{b} \\
{[\mathrm{~ms}]}\end{array}$ & $N_{\text {guest }^{c}}$ & $\begin{array}{c}\text { Efficiency }^{d} \\
\left(N_{\text {guest }} / N_{\mathrm{RF}}\right)\end{array}$ \\
\hline S1 & 177 & 15 & 40 & 0.24 \\
S2 & 472 & 24 & 80 & 0.54 \\
S3 & 136 & 8.2 & 106 & 0.64 \\
S4 & 69 & 5.6 & 250 & 1.29 \\
S5 & 69 & 7.4 & 260 & 0.77 \\
\hline
\end{tabular}

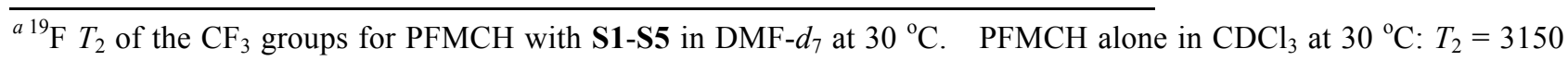
ms.

${ }^{b}{ }^{19} \mathrm{~F} T_{2}$ of the in-core $\mathrm{CF}_{3}$ groups for S1-S5 with PFMCH in DMF- $d_{7}$ at $30{ }^{\circ} \mathrm{C}$.

${ }^{c}$ The number of PFMCH encapsulated within a star polymer in DMF- $d_{7}$.

${ }^{d}$ Encapsulation efficiency of PFMCH per an in-core $\mathrm{R}_{\mathrm{f}} \mathrm{MA}$ unit: $N_{\text {guest }} / N_{\mathrm{RF}}\left(N_{\mathrm{RF}}\right.$ : see Table 1$)$. 


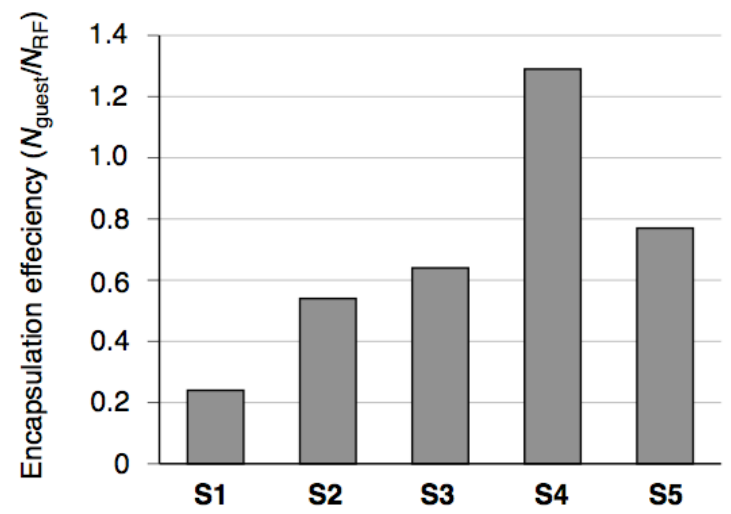

Figure 6. Encapsulation efficiency $\left(N_{\text {guest }} / N_{\mathrm{RF}}\right)$ of PFMCH into S1-S5 per an in-core $\mathrm{R}_{\mathrm{F}} \mathrm{MA}$ unit in DMF- $d_{7}$ at $30{ }^{\circ} \mathrm{C}$. 
(a)

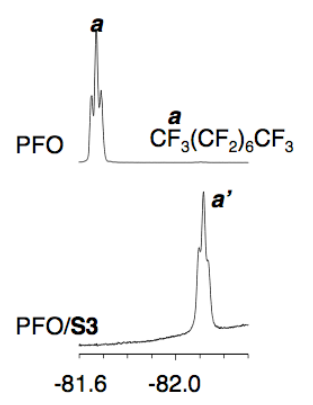

(b)

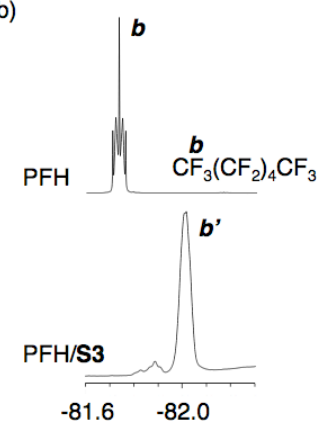

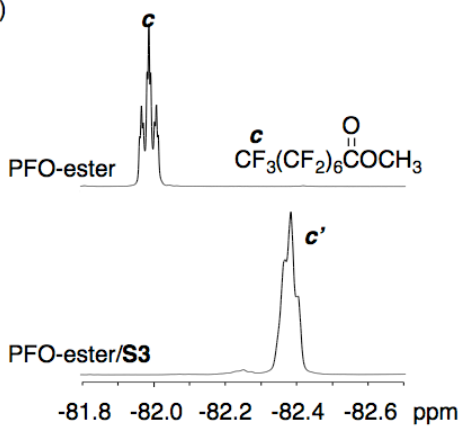

(d)

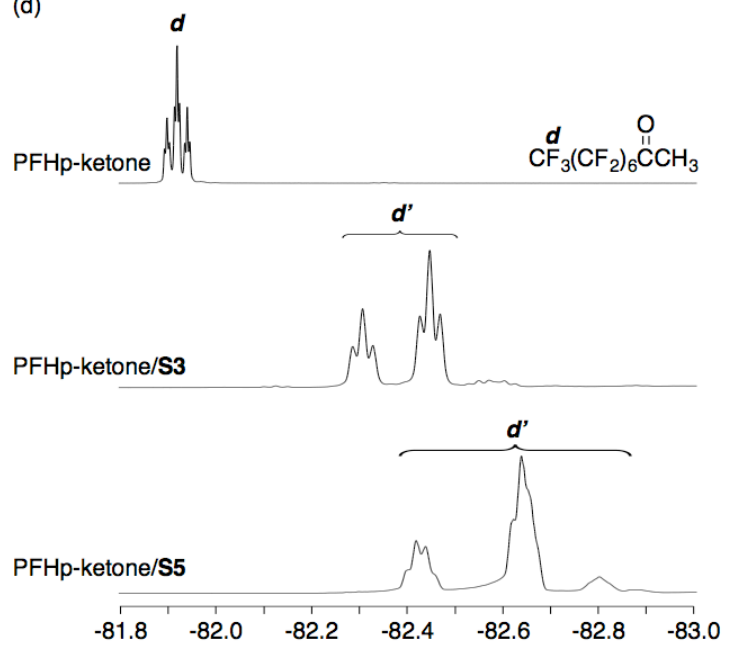

(e)

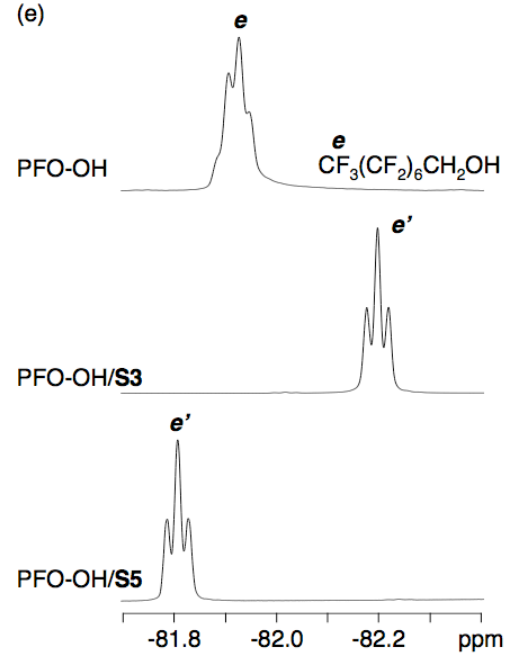

Figure 7. ${ }^{19} \mathrm{~F}$ NMR $(470 \mathrm{MHz})$ spectra of polyfluorinated guests (a: PFO, b: PFH, c: PFO-ester, d: PFHp-ketone, e: PFO-OH) with S3 or S5: [S3 or S5] $=50 \mathrm{mg} / \mathrm{mL}$ in DMF- $d_{7}$ at $30{ }^{\circ} \mathrm{C}$. 

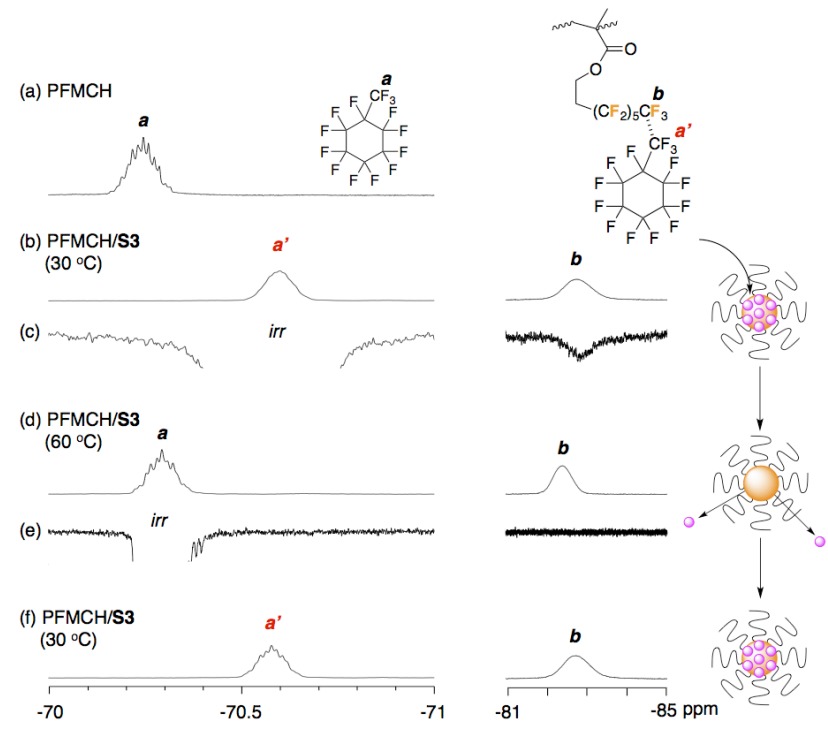

Figure 8. ${ }^{19} \mathrm{~F}$ NMR (470 MHz) spectra of (a) PFMCH alone in DMF- $d_{7}$ at $30{ }^{\circ} \mathrm{C}$ and PFMCH with $\mathbf{S 3}$ in DMF- $d_{7}$ at (b, f) 30 and (d) $60{ }^{\circ} \mathrm{C}$. ${ }^{19} \mathrm{~F}$ nuclear Overhauser effect (NOE) difference spectra of PFMCH with S3 in DMF- $d_{7}$ at (c) 30 and (e) $60{ }^{\circ} \mathrm{C}$. 
(a)
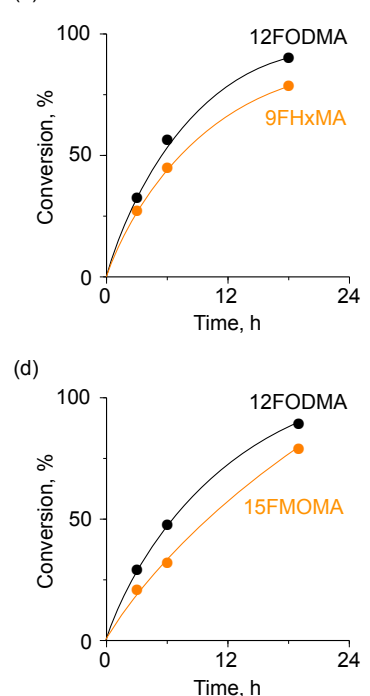

(b)

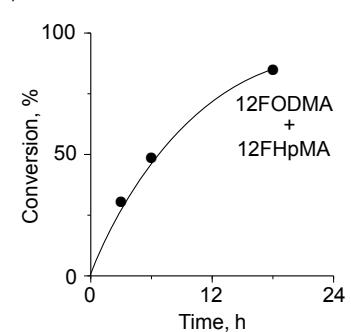

(e)

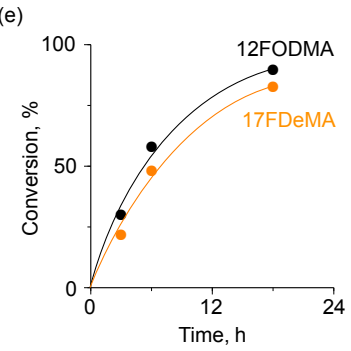

(c)

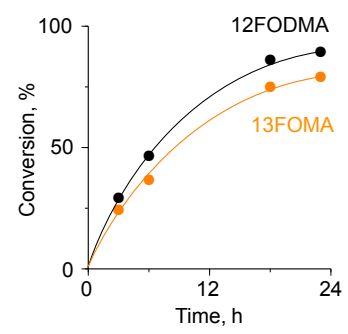

Figure S1. Time-conversion curves in the linking reaction of PMMA-Cl arms with 12FODMA

(1) and $\mathrm{R}_{\mathrm{f}} \mathrm{MA}$ (a: 9FHxMA b: 12FHpMA c: 13FOMA, d: 15FMOMA, e: 17FDeMA) for (a) S1, (b) S2, (c) S3, (d) S4, and (e) S5. 